\title{
Prevention of Mental Health Difficulties for Children Aged 0-3 Years: A Review
}

\author{
Elizabeth Izett ${ }^{1}$, Rosanna Rooney ${ }^{1 *}$, Susan L. Prescott ${ }^{2}$, Mia De Palma ${ }^{1}$ and \\ Maryanne McDevitt ${ }^{1}$
}

${ }^{1}$ School of Psychology, Faculty of Health Sciences, Curtin University, Perth, WA, Australia, ${ }^{2}$ The ORIGINS Project, Telethon Kids Institute and the Division of Paediatrics, School of Medicine, University of Western Australia, Nedlands, WA, Australia

\section{OPEN ACCESS}

Edited by:

Nuno Barbosa Rocha,

Polytechnic of Porto, Portugal

Reviewed by:

Rosa Angela Fabio

University of Messina, Italy

Maria Fernanda Lara-Diaz, National University of Colombia,

Colombia

*Correspondence:

Rosanna Rooney

r.rooney@curtin.edu.au

Specialty section:

This article was submitted to Psychology for Clinical Settings,

a section of the journal

Frontiers in Psychology

Received: 25 September 2019 Accepted: 24 September 2020 Published: 29 September 2021

Citation:

Izett E, Rooney R, Prescott SL, De Palma M and McDevitt M (2021) Prevention of Mental Health Difficulties

for Children Aged 0-3 Years:

A Review. Front. Psychol. 11:500361. doi: 10.3389/fpsyg.2020.500361
The period of infancy and early childhood is a critical time for interventions to prevent future mental health problems. The first signs of mental health difficulties can be manifest in infancy, emphasizing the importance of understanding and identifying both protective and risk factors in pregnancy and the early postnatal period. Parents are at a higher risk of developing mental health problems during the perinatal period. An understanding of the evidence around prevention and intervention for parental anxiety and depression is vital to the process of prevention of early mental health disorders in infants and young children. Here we review the existing prevention and treatment interventions in the early years focusing on the period from conception to 3 years - the majority targeting parents in order to improve their mental health, and that of their infants. Elements of successful programs for parents include psychoeducation and practical skills training, as well as work on the co-parenting relationship, developing secure attachment, and enhancing parental reflective functioning. While both targeted and universal programs have produced strong effect sizes, universal programs have the added benefit of reaching people who may otherwise not have sought treatment. In synthesizing this information, our goal is to inform the development of integrated models for prevention and novel early intervention programs as early in life as possible.

Keywords: early intervention, parent mental health, early childhood mental health, infants and toddlers, intervention and prevention, parenting programs, zero to three

\section{INTRODUCTION}

Across the world, $10-20 \%$ of children and adolescents suffer from mental health disorders (Kessler et al., 2007). If not treated, mental health disorders of childhood have a severe, negative impact on children's development and their long-term capacity to live healthy, productive and fulfilling lives (Lyons-Ruth et al., 2017). Mental health disorders have a profound impact on all aspects of health, happiness and productivity. The personal, social and economic costs of mental health difficulties are high, including clinical and education services, sick-leave and unemployment, and the criminal justice system (Bor et al., 2004). The direct and indirect economic cost of mental illness in Australia has been estimated at $\$ 20$ billion per year, which includes the cost of lost productivity and labor force participation (Department of Health and Ageing, 2007). The burden of illness from mental health disorders accounts for approximately $12 \%$ of the total disability-adjusted 
life years associated with all illnesses, the third highest after cancer and cardiovascular diseases (Australian Institute of Health and Welfare, 2016).

As mental health difficulties early in life have a significant impact on the future health trajectory of an individual, it is essential to build the foundations of good mental health during this critical period (Lewis et al., 2014; Moore et al., 2017). In this review, we consider interventions offered at the earliest opportunity spanning from the perinatal period to 3 years of age aimed at preventing mental health difficulties in childhood. We begin with a description of mental health in infancy and early childhood and go on to present the current prevalence statistics within the population. We then consider the factors that contribute to, or detract from, good mental health during infancy and early childhood, including parent-child attachment, parental reflective functioning, parental mental health, co-parenting and the couple relationship as well as childhood experiences recognizing that these factors can be used to inform prevention and early intervention efforts (Bayer et al., 2008). Interventions that aim to improve parent mental health during this period are also considered, given that parental mental health has been found to be a risk factor for poor outcomes in infants and children, including emotional and conduct problems later in life (Bauer et al., 2016). Finally, we explore the current approaches to prevent mental health problems during infancy, and how these might be extended.

\section{MENTAL HEALTH PROBLEMS IN INFANCY AND EARLY CHILDHOOD}

The current statistics indicate an alarming rate of mental health problems in children and adolescents. As noted above, 10-20\% of children and adolescents experience mental health problems worldwide (World Health Organization, 2003). While it is widely accepted that we are in the midst of a mental health crisis for young people, what is often missed is that the precursors of mental health problems can begin as early as the perinatal period and early infancy (Robinson et al., 2008). This makes the perinatal, infant and early childhood period a crucial window for intervention, with the goal of promoting good mental health for infants and young children (Robinson et al., 2008).

Good mental health in infancy and early childhood refers to healthy social and emotional development. It includes an infant's ability to experience, regulate and express emotions, to develop close and secure interpersonal relationships, and to explore the environment and learn (Clinton et al., 2016). All of these capacities develop best within the context of a caregiving environment that includes family, community, and cultural expectations for young children (Parlakian and Seibel, 2002).

Research has established that infants and toddlers can suffer from mental health disorders that require treatment in their own right (Warner and Pottick, 2006; Zero to Three, 2012). Difficulties in infancy include regulatory disturbances such as excessive crying, sleeping or feeding difficulties and attachment difficulties (Postert et al., 2012; ZERO TO THREE, 2016). Early childhood mental health problems include externalizing problems such as aggression and oppositional defiance (Egger and Angold, 2006; Loeber et al., 2009), and internalizing problems such as anxiety and depression (Costello et al., 2005; Rapee et al., 2009; Bayer et al., 2011).

Several epidemiological studies have determined the prevalence of mental health disorders in infants and young children, indicating a $16-18 \%$ prevalence of mental health disorders amongst children aged 1-5 years, with approximately half of these children being severely impacted (von Klitzing et al., 2015). One birth cohort study found that almost 35\% of infants aged 12-18 months scored high on the Problem Scale of the Brief Infant Toddler Social Emotional Assessment (BITSEA) (Horwitz et al., 2013), while another study found that by 18 months of age, $16-18 \%$ of children met criteria for one or more diagnoses of a mental health or developmental disorder (Skovgaard et al., 2007). Similar results were reported by an Australian study, which found that by 2 years of age, $12 \%$ of children had clinically significant emotional, behavioral, or social problems in the context of parent-child relationship disturbance (Bayer et al., 2011). In addition to this, a Western Australian study found that by age five, $20 \%$ of the children studied had clinically significant behavioral problems (Robinson et al., 2008). As noted by LyonsRuth et al. (2017), most recent epidemiological studies have been conducted in developed, economically stable, peaceful countries. However, evidence suggests that rates of mental health difficulties may be much higher in countries where extreme poverty, war, family displacement and trauma exist (Tomlinson et al., 2014).

Mental health problems in infants and toddlers are strongly predictive of poor mental, physical, cognitive, and social outcomes during childhood, adolescence and adulthood. Regulatory problems in infancy are associated with later motor, language and cognitive delays, behavioral problems and ongoing parent-child relationship difficulties (DeGangi et al., 2000; Hemmi et al., 2011; Cook et al., 2019). In one longitudinal study, when children were followed up to the their early schooling, two-thirds of the infants and toddlers (aged 12 to 40 months) who had earlier emotional and behavioral difficulties continued to have ongoing difficulties with persistent psychopathology (Briggs-Gowan et al., 2006). Another study found difficult temperament, non-compliance and aggression in infancy and toddlerhood (age one to three years) was associated with internalizing and externalizing psychiatric disorders at five years of age (Keenan et al., 1998).

If not treated, mental health difficulties that begin early in life can become more serious over time (Lavigne et al., 1998; Shaw et al., 2003; Briggs-Gowan et al., 2006; Suveg et al., 2007; Slemming et al., 2010; Clinton et al., 2016), and can persist into adolescence and adulthood (Bor et al., 2004; National Scientific Council on the Developing Child, 2008; Bayer et al., 2011). Children with mental health problems are at higher risk for difficulties at school, difficulties with peers, difficulty participating in employment, drug and alcohol problems, relationship breakdown, family violence, criminal activity, juvenile delinquency and suicide (Bayer et al., 2008; National Scientific Council on the Developing Child, 2008). Consequently it is vital to provide interventions that aim to prevent mental health difficulties from developing at this early age. 


\section{RISK FACTORS FOR INFANT AND EARLY CHILDHOOD MENTAL HEALTH PROBLEMS}

There is international consensus that the first 1,000 days of life - the period of development from conception to age two represent a crucial period of rapid physical, psychological and neurological growth (Moore et al., 2017). During this time there is an increased likelihood that detrimental experiences such as early trauma or deprivation will be especially harmful and greatly impact future development, with adverse effects potentially going on to develop into lifelong consequences (Shonkoff et al., 2012; Lyons-Ruth et al., 2017; Moore et al., 2017).

Researchers have identified several risk factors for poor mental health in infants, taking into account the interaction between the individual child's genetics, temperament and environment (McLuckie et al., 2019). Risks in the child include the presence of physical health difficulties, a difficult temperament, and insecure and disorganised attachment patterns (Bosquet and Egeland, 2006; Van Zeijl et al., 2006; Miner and Clarke-Stewart, 2008; Edwards et al., 2010; Wlodarczyk et al., 2017). Family based risk factors include parenting interactions that are insensitive, lack warmth, or are controlling, as well as parental interactions that are over involved or over protective. Other factors include overly harsh discipline, parental mental health difficulties or stress, parental substance abuse, family violence, limited parental education, and parental conflict or separation/divorce (Dwyer et al., 2003; McCarty et al., 2005; Bayer et al., 2006, 2011; Pike et al., 2006; Van Zeijl et al., 2006; Ashford et al., 2008; Miner and Clarke-Stewart, 2008; Edwards et al., 2010; Wlodarczyk et al., 2017).

The experience of trauma during infancy, including maltreatment, exposure to domestic violence, and disruption of attachment relationships are significant developmental risk factors that lead to vulnerabilities to later mental health difficulties (Newman et al., 2016). The Adverse Childhood Experiences (ACE) study found that trauma that occurs early in development is associated with an increased risk of mental health problems and chronic diseases later in life including depression, suicide attempts, substance use, teen pregancy, heart disease, cancer, lung disease and liver disease (Felitti et al., 1998; Campbell et al., 2014). Furthermore, this level of risk increases exponentially with increased adverse childhood experiences. Researchers have found that individuals with four or more adverse childhood experiences are at significantly higher risk of developing a mental health problem than individuals with none (Felitti et al., 1998). Epigenetic studies have found that early childhood maltreatment is linked to higher methylation of key genes related to the stress response. These methylation changes place children at risk of cancers, cardiovascular disease, autoimmune disorders, and psychiatric disorders (Perry, 2004; Cicchetti et al., 2016). Environmental stressors such as war, natural disasters and family dislocation also place infants and young children at risk of mental health difficulties, especially if the primary caregiver is rendered less emotionally available by the same stressor (Lyons-Ruth et al., 2017).

\section{PARENT DEPRESSION AND ANXIETY DURING THE PERINATAL AND INFANCY PERIODS}

The perinatal period is a vulnerable time for parent stress and mental health difficulties (Jones et al., 2014). Perinatal depression affects approximately $11.9 \%$ of pregnant women worldwide (Woody et al., 2017). This value is from a study of pooled prevalence analyzing 96 prevalence studies from across the globe (Woody et al., 2017). Postnatal depression is associated with a disruption in the parent-infant attachment relationship which can place the infant at increased risk of mental health difficulties (Lyons-Ruth et al., 2017), it is also related to poor outcomes in cognitive and emotional development of children, and increased risk of psychopathology (Kingston et al., 2012). Anxiety related disorders are also prevalent during the perinatal period, with approximately $15 \%$ of women experiencing anxiety (Fairbrother et al., 2016). Perinatal anxiety is also related to poor outcomes in children, with increased incidence of internalizing disorders, somatic problems and behavioral inhibition found in children whose mothers experienced anxiety related disorders in the perinatal period (Bauer et al., 2016). Another metaanalysis focused on comorbid depression and anxiety during the perinatal period (Falah-Hassani et al., 2017). This is noteworthy as comorbid disorders tend to present a higher risk than single disorders. The prevalence of comorbid depression and anxiety symptoms during the perinatal period was $8.1 \%$, and the prevalence of a diagnosed comorbid disorder was $7.9 \%$ (Falah-Hassani et al., 2017). These results indicate that comorbid depression and anxiety impact one in ten women during pregnancy and one in twelve women during the postnatal period (Falah-Hassani et al., 2017).

Perinatal depression in fathers has been less researched but is being increasingly recognized as important for ongoing child wellbeing (Philpott and Corcoran, 2018). A meta-analysis found that rates varied across studies, but the average prevalence of depression in fathers across the perinatal period was $8.4 \%$, with similar rates in the prenatal and postnatal periods (Cameron et al., 2016). This is higher than the rate of depression in the general population (Philpott and Corcoran, 2018). It is important to note that the prevalence of perinatal depression in fathers was not much lower than the average prevalence for mothers (Woody et al., 2017). There is also a positive correlation between maternal and paternal depression (Cameron et al., 2016; Philpott and Corcoran, 2018).

There are a number of risk and protective factors that have been identified for perinatal depression and anxiety in parents. Risk factors include a history of depression and anxiety, lack of support and difficulty bonding with the new baby (PANDA, 2017). Mothers who have difficulty soothing their baby and getting them to sleep have a higher risk of mental health problems. Parents whose partners are depressed are also at higher risk of developing perinatal depression (Cameron et al., 2016). Parental anxiety and depression pose significant risks to the developing infant's mental health (Bauer et al., 2016). Poor parental mental health during the transition to parenthood can 
have long lasting consequences for the infant, impacting their developmental trajectory and future mental health and wellbeing (Bauer et al., 2016). Consequently, programs aimed at enhancing mental health in infancy and early childhood should focus on parent mental health, as parent wellbeing during this time plays an important role in ensuring the positive mental health of their children.

Cognitive-behavioral therapy and interpersonal psychotherapy have been identified in a review as effective treatment approaches for pregnant women with major depressive disorder, suggesting that interventions should be based on these approaches (Van Ravesteyn et al., 2017).

A review of prevention programs for postnatal depression found that those using interpersonal therapy were the most consistent in delivering effective results (Werner et al., 2016). Mixed results were seen for cognitive behavioral programs, although individual interventions appeared more effective than group-based interventions (Werner et al., 2016).

Cognitive Behavioral interventions in the perinatal period have been found to be an effective intervention treatment for depression (Gloaguen et al., 1998; Barkham et al., 1999; Sockol, 2015; Ziemeng et al., 2020; Holt et al., 2021). These interventions have typically targeted evaluating potentially problematic styles such as catastrophic thinking and including behavioral strategies such as relaxation to assist in coping with stressful situations.

\section{ATTACHMENT AND MENTALIZATION}

Attachment theory asserts that the relationship between the infant and their primary carers has an important influence on the development of the capacity for emotional and behavioral regulation (Bowlby, 1969; Ainsworth et al., 1978). A large body of evidence has identified that an infant's developing brain is shaped by the quality of the caregiving environment provided by their primary caregivers (Kerns and Brumariu, 2014; Lally and Mangione, 2017). Secure primary attachment relationships, although not a guarantee against future mental health difficulties, are influential protective factors for infant and young children's mental health. A secure attachment relationship allows the infant's developing brain to develop capacities in building and maintaining relationships, emotional regulation, attention and self-control and sets a strong foundation for the later development of resilience, confidence and adaptability (Benoit, 2004; Balbernie, 2013). Researchers have consistently found that securely attached children experience stronger relationships with their parents as well as enhanced problem solving abilities, improved peer relationships and longer lasting friendships (Schneider et al., 2001; Abraham and Kerns, 2013; Guild et al., 2017). These children may also have better sibling relationships, more positive self-esteem, an increased sense of hopefulness, greater trust in people and relationships, and heightened optimism about their future compared to children with insecure attachment styles. In contrast, insecure and disorganised attachment styles in infancy have been associated with elevated rates of emotional, social and behavioral disturbances in infancy, toddlerhood, preschool and beyond (Van
Ijzendoorn et al., 1999; Granot and Mayseless, 2001; Sroufe, 2005; Berlin, 2008; Fearon et al., 2010; Madigan et al., 2013). A 30-year prospective study of infants with insecure attachment styles at 8 months of age, found insecure attachment to be associated with a higher risk of mental health concerns at 30 years of age (Fan et al., 2014). Disorganised attachment in infancy is associated with the highest risk of later social and cognitive difficulties and psychopathology with an association found between disorganised infant attachment and childhood behavior problems (Van Ijzendoorn et al., 1999), externalizing and internalizing problems in early school years, aggression and oppositional defiant disorder (Green and Goldwyn, 2002; Fearon et al., 2010), and personality disorder (Steele and Siever, 2010). Studies have found disorganised attachment is significantly correlated with psychopathology in adolescence (Carlson et al., 1998), borderline personality disorder symptoms in adulthood (Carlson et al., 2009), dissociation (Lyons-Ruth, 2003); and posttraumatic stress disorder (PTSD) (Macdonald et al., 2008).

Ideally, parents and caregivers are able to tune into their baby's cues, interpret their meaning, and respond to them in a contingent, consistent and competent way, which has been termed sensitive parenting (Petch et al., 2012; Ensink et al., 2016). Parents who provide care in this way allow their infant to develop optimal early social-emotional skills, secure infantparent relationships and cognitive ability (The National Health and Medical Research Council, 2017). One way to understand the connection between sensitive parenting, attachment and later functioning is through the concept of mentalization. Fonagy and colleagues drew on the fields of psychoanalytic theory, attachment theory, theory of mind and developmental psychology to develop the concepts of mentalization theory (Fonagy et al., 1991, 2002; Fonagy and Target, 1997). They defined mentalizing capacity as the ability to understand that that one's own behavior and the behavior of others is driven by internal states, such as intentions, thoughts, desires, feelings, beliefs, goals and motivations. They proposed that mentalizing capacity develops within the context of a secure attachment relationship (Fonagy et al., 2002), and is key to understanding the association between insecure attachment and psychopathology. Parental mentalizing has been operationalized as parental Reflective Functioning (PRF), and refers to the quality of mentalizing in the context of attachment relationships, and the parent's capacity to think about mental states in relation to their own and their child's behavior. Parental RF is considered to play an important role in parenting, and therefore the development of children's attachment security (Stacks et al., 2014; Ensink et al., 2016; Camoirano, 2017; Barlow et al., 2021). Parents with higher PRF display more sensitivity in their interactions with their infants, and are more likely to have securely attached infants (Grienenberger et al., 2005; Slade et al., 2005a; Rosenblum et al., 2008). Parents with low PRF are more likely to display insensitive parenting and to have to have children with insecure or disorganized attachment styles (Grienenberger et al., 2005; Slade et al., 2005a; Suchman et al., 2010; Stacks et al., 2014; Ensink et al., 2015, 2019).

Only a few studies have been conducted to investigate the connection between parental RF and early childhood 
psychopathology. These studies have investigated the role of parental RF on the development of child emotional regulation and anxiety symptoms (Camoirano, 2017). Esbjørn et al. (2013) found that low maternal RF predicted higher levels of anxiety amongst clinically anxious school aged children. Heron-Delaney et al. (2016) found that preterm infants with mothers with high RF demonstrated the most negative effects and better selfsoothing behavior during the still face procedure compared to infants with mothers with low RF. They surmised that high maternal RF promotes emotional regulation in the infant when distressed, and higher trust in maternal responsiveness. Smaling et al. (2016) found that high risk young pregnant women with higher RF reported significantly lower aggressive behaviors in their children when they were 6, 2, and 20 months old. Ensink et al. (2016) found that maternal RF was found to correlate with child reflective functioning, and negatively with child externalizing behaviors. These findings suggest that maternal mentalizing capacity plays an important role in promoting infant and child emotional regulation, especially in the context of difficult early childhood experiences (Camoirano, 2017). Consequently, enhancing parental mentalizing capacity and parent child attachment security will promote positive mental health in infants and young children, and may work toward preventing mental health difficulties.

To date, most research in this field has focused mainly on the role of mothers. Evidence suggests that mothers and fathers play different and unique roles roles as attachment figures and in socialization and emotion regulation (Benbassat and Priel, 2015; Buttitta et al., 2019). Research is expanding to consider the impact of paternal reflective functioning on child development (Sarkadi et al., 2008; Benbassat and Priel, 2015; Cooke et al., 2017).

\section{CO-PARENTING AND THE COUPLE RELATIONSHIP}

In addition to the development of mental health difficulties, many couples also experience a sharp decline in their couple relationship during the transition to parenthood (Lawrence et al., 2008; Doss et al., 2009). In fact, a decline in relationship satisfaction can act as a risk factor for the development of mental health difficulties (Lancaster et al., 2010; Whisman et al., 2011; Giallo et al., 2013; Bayrampour et al., 2015). Meanwhile the inverse may also be true, wherein mental health difficulties may act as a contributing factor for relationship decline (Whisman et al., 2011; Trillingsgaard et al., 2014). Furthermore, researchers have shown that a strong couple relationship can act as a protective factor against the development of perinatal depression and anxiety in both parents (Banker and LaCoursiere, 2014; Pilkington et al., 2015). The couple relationship also has strong links to child outcomes (Cowan and Cowan, 2002; Harold and Leve, 2012). For example, relationship discord in parents has been associated with, poor child adjustment (Hanington et al., 2012), anxiety and depression (Yap et al., 2014), aggression (Cowan and Cowan, 2002), poor academic attainment (Harold et al., 2007) and behavioral issues (Linville et al., 2010). Having a positive couple relationship has also been linked to more responsive parenting (Ponnet et al., 2013). These findings reinforce the importance of the couple relationship during the transition to parenthood.

However, another body of research has gone on to highlight the importance of an additional related, but distinct aspect of the parental relationship, known as coparenting (Feinberg, 2002). Coparenting is defined as the degree to which parents are able to work together harmoniously for the wellbeing of their children (Le et al., 2016). As with relationship satisfaction, coparenting has been linked to a variety of child outcomes (Le et al., 2016), including psychological adjustment (Teubert and Pinquart, 2010), attention and educational achievement (Dopkins Stright and Neitzel, 2003) along with the development of receptive language and social relationships (Cheng et al., 2009). Coparenting has also been related to parenting practices including sensitivity and warmth within parent-child interactions (Cabrera et al., 2009). In fact, some research suggests that coparenting may act as a mediating factor in the link between relationship satisfaction and positive parenting practices (Bonds and Gondoli, 2007; Pedro et al., 2012). In line with this, a large body of research has found a link between relationship satisfaction and positive coparenting (Christopher et al., 2015; Le et al., 2016; Durtschi et al., 2017). Furthermore, in addition to links between coparenting, relationship satisfaction and child outcomes, Feinberg and colleagues have also shown that targeting the coparenting relationship can have a positive impact on parental mental health (Feinberg and Kan, 2008; Feinberg et al., 2016). This research overall demonstrates the importance of coparenting and the couple relationship for both parent and child wellbeing during the transition to parenthood.

\section{NEED FOR PREVENTION AND EARLY INTERVENTION}

This body of literature highlights the importance of childhood experiences across the lifespan, starting in the perinatal period, emphasizing the importance of addressing risk factors early in life (Felitti et al., 1998; Jones et al., 2018b). The cost of mental health disorders on individuals and society demands a response that focuses on early investment, health promotion and early intervention in an effort to positively impact future health (Jenkins et al., 2002). The World Health Organization has asserted that prevention is the only sustainable approach for reducing the burden of illness associated with mental disorders (World Health Organization, 2004). It is well established that early detection, assessment and intervention of mental health problems in infancy and early childhood is more successful and cost effective than treatment when symptoms become more severe (Davis et al., 2010; Huberty, 2012; The National Health and Medical Research Council, 2017).

This shift in focus toward the prevention of mental illness means that we must consider the mental health and wellbeing of infants and young children, as well as their parents (Guy et al., 2016). While the period of infancy and early childhood is a time when mental health difficulties can develop, it is 
also an enormously influential developmental stage with the potential to modify or prevent the development of dysfunctional pathways (Karevold et al., 2009; Lewis et al., 2014; Moore et al., 2017). Because many disorders can be prevented through developmentally appropriate, high quality programs and services, it is becoming increasingly acknowledged that it is not enough to merely treat mental health disorders as they emerge (Andrews and Wilkinson, 2002; Waddell et al., 2007). Instead, research suggests that efforts should focus on the prevention of mental health difficulties before they arise, particularly during the earliest stages of life when there is the greatest capacity to effect change (Maldonado-Duran et al., 2000; Bayer et al., 2010b; The National Health and Medical Research Council, 2017).

Focused interventions early in life are one effective method to address these risk factors and reduce and prevent poor outcomes in infants and young children before they emerge, allowing for better outcomes later in life. An increased emphasis on the importance of the perinatal and infancy period has contributed to the development of programs that aim to either prevent the emergence of mental health disorders or intervene early if they do develop (Van Ravesteyn et al., 2017). Prevention refers to any approach that is applied in an effort to prevent later difficulties and to enhance the cognitive, behavioral, emotional, social and physical development of young children during the period from pregnancy to 6 years of age (Zero to Three, 2012; Dunst et al., 2014). Prevention programs are often offered on a community wide basis, especially in high-risk communities; they serve to intervene early and support parents and caregivers to provide sensitive, warm and secure relationships and detect emotional problems before they become more resistant to change (Mihelic et al., 2017).

Early intervention refers to interventions offered once an infant/child or their parents are identified as significantly at risk or the child is already showing some type of difficulty that is seen as placing their development at risk (Dunst et al., 2014). Over the past decade, several perinatal and infancy prevention/early intervention programs have been developed and evaluated, with some designed for universal implementation and others designed to be implemented in communities who are at increased risk of poor social and emotional development. These programs aim to improve mental health in both parents and children, and are a window of opportunity through which to enhance the social and emotional development of infants and young children (Watson et al., 2005). In this article, we look at the existing programs that have been developed as interventions during the early years of life. This is important to identify which programs and approaches are most effective, and to build on the research that has been conducted over the past years.

\section{METHOD}

This review aimed to look at (1) the existing programs targeting mental health in children aged $0-3$ and their parents (2) the components and efficacy of these programs.

A search was conducted across multiple online databases, including PsychInfo, Informit, Scopus, ProQuest, Wiley Online
Library, Science Direct, PubMed and Google Scholar. Reference tracking of relevant articles was also used, and websites of specific programs were searched for reference lists. The search terms used in the databases included: perinatal mental health, infant mental health, early life programs, parenting interventions, prevention, anxiety, depression, coparenting, reflective functioning, mentalization, attachment. An initial search using these terms generated 10,809 peer reviewed articles. These were further narrowed down according to inclusion and exclusion criteria, through specification of search terms and visual inspections of titles and abstracts.

Articles were included if they were: written in English, detailed an intervention or program for children aged 0-3 years, and were focused on the mental health of parents or children. Articles were excluded if they were: not in English, did not contain an intervention or program, involved programs directed at older children, or involved programs solely focused on medical or physical aspects of infant health, e.g., premature birth. The search was concluded on the 20th March, 2020, resulting in 60 articles reporting 27 interventions that were relevant to the current review. Of the 60 articles, 9 were descriptive only, leaving 51 articles that reported original data and results of programs.

In this review, we have included effect sizes for programs where they were reported or where there was enough information reported to calculate them manually (Lakens, 2013). Instead of providing descriptions of effect sizes throughout the review, they are detailed below (see Table 1). Details of the included articles are outlined briefly (see Table 2) and then described more extensively.

\section{RESULTS}

Due to the young age of the children concerned in this review, the majority of the programs (24) found in our search were designed to be presented to parents, addressing parental factors that would impact their infants and toddlers. Only a few (3) of the programs were designed to be presented specifically to children (Relationships for Growth and Learning, Early Head Start, and Responsive Early Childhood Curriculum).

The highest proportion of existing programs were targeted interventions for at-risk mothers (PREPP, ROSE Program, PEEP Reflective Parenting Program, Lighthouse Parenting Program, Minding the Baby, Mindful Motherhood, AMPLE, CAPEDP, Mom Power, Playing and Learning Strategies, HUGS and an unnamed antenatal group program). Across programs, a number of different maternal risk factors were used as inclusion criteria

TABLE 1 | Effect sizes.

\begin{tabular}{lccc}
\hline Effect size & Small & Medium & Large \\
\hline$d$ & 0.20 & 0.50 & 0.80 \\
$r$ & 0.10 & 0.30 & 0.50 \\
$\eta_{p}^{2}$ (partial eta squared) & 0.01 & 0.06 & 0.14 \\
$g$ & 0.20 & 0.50 & 0.80 \\
ES (effect size for one group design) & 0.20 & 0.50 & 0.80
\end{tabular}




\section{Interventions that target maternal mental health}

Mindful Motherhood

Vieten and Astin, $2008 \quad 31$ mothers, targeted ROSE Program
Zlotnick et al., 2001
37 mothers, targeted
Zlotnick et al., 2006
mothers, targeted
N/A
Johnson et al., 2018

\section{作}

\section{Toward Parenthood}

$$
\text { Milgrom et al., } 2011
$$

143 mothers, universa PREPP

Werner et al., 2016

54 mothers, targeted

Mothers and Babies

Munoz et al., 200

Tandon et al., 2011

Le et al., 2011

Mendelson et al., 2013

Tandon et al., 2014

Leis et al., 2015

McFarlane et al., 2017

Tandon et al., 2018

CAPEDP

Saias et al., 2013

Dugravier et al., 2013

Antenatal group program

Thomas et al., 2014

41 mothers, targeted

61 mothers, targeted

217 mothers, targeted

78 mothers, targeted

78 mothers, targeted

15 mothers, targeted

5 mothers, targeted

120 mothers, universa

$\mathrm{N} / \mathrm{A}$

440 mothers, targeted

48 mothers, targeted

interventions that target fathers

Boot Camp for New Dads

$$
\begin{array}{ll}
\text { Capuozzo et al., 2010 } & \text { N/A } \\
\text { Miller, 2012 } & \text { 2301 fathers, universal }
\end{array}
$$

Interventions that target the couple relationship

Couple CARE for Parents
Halford et al., 2010
71 couples, universal
Petch et al., 2012
250 couples, targeted
Heyman et al., 2019
368 couples, targeted

Interventions that target the mother-infant relationship AMPLE

Nicolson et al., $2013 \quad 97$ mothers, targeted
Waitlist control

Treatment as usual

Standard antenatal care

N/A

Routine care

Enhanced treatment as usual

Usual medical care

Standard visits plus information

Usual care

Standard visits plus information

Home visiting as usual

No control group

Home visiting as usua

Home visiting as usua

N/A

Usual care

No control group

N/A

No control group

Maternal parenting program

Maternal parenting program

Waitlist control
Anxiety (L), negative affect (L)

Depressive symptoms (?), risk of developing PND (?)

Risk of developing PND (?)

N/A

Depression $(M)$, anxiety $(M)$, stress $(M)$, parenting dysfunction $(M)$

Depressive symptoms (L), anxiety symptoms (M)

No significant effects

Depressive symptoms (S)

No significant effects

Mood regulation (?)

Depressive symptoms (L)

Depressive symptoms (L), mood regulation $(L$

Depressive symptoms (S, stress (S)

Depression (M), anxiety (S)

N/A

Depression for low-risk mothers (?)

Depression (L), anxiety $(\mathrm{L})$, maternal attachment $(\mathrm{M})$

N/A

Parenting confidence (?)

Couple conflict $(L)$, invalidation $(L)$, negative affect $(L)$, women's relationship adjustment $(M)$, self-regulation $(L)$

Conflict for women $(M)$, invalidation for women (L)

No significant effects 


\begin{tabular}{|c|c|c|c|}
\hline Program and author & Participants & Control group & Significant effects and size ( $\mathrm{S}=$ small, $M=$ medium, $L=$ large, $?=$ not provided) \\
\hline \multicolumn{4}{|l|}{ Mom Power } \\
\hline Muzik et al., 2015 & 99 mothers, targeted & No control group & Depressive symptoms (?), PTSD symptoms (?), caregiving helplessness (?), parenting reflectivity (?) \\
\hline Muzik et al., 2016 & 49 mothers, targeted & No control group & Depressive symptoms (?), PTSD symptoms (?) \\
\hline Rosenblum et al., 2017 & 122 mothers, targeted & Mailout information & $\begin{array}{l}\text { PTSD symptoms (S), parenting stress (S), depressive symptoms [iatrogenic] (S), depressive } \\
\text { symptoms in women with IPV history (M), PTSD symptoms in women with IPV history (M) }\end{array}$ \\
\hline Rosenblum et al., 2018 & 75 mothers, targeted & Mailout information & Reflective parenting (S) \\
\hline \multicolumn{4}{|l|}{ Playing and Learning Strategies } \\
\hline Landry et al., 2006 & 242 mothers, targeted & $\begin{array}{l}\text { Developmental assessment } \\
\text { sessions }\end{array}$ & $\begin{array}{l}\text { Contingent responsiveness }(L) \text {, support of infant foci of attention }(M) \text {, verbal scaffolding }(L) \text {, object } \\
\text { labeling }(L) \text {, smiling and laughing [iatrogenic] }(M)\end{array}$ \\
\hline Landry et al., 2008 & 166 mothers, targeted & $\begin{array}{l}\text { Developmental assessment } \\
\text { sessions }\end{array}$ & $\begin{array}{l}\text { Verbal encouragement (S), child cooperation (S), social engagement (S), contingent responsiveness } \\
\text { (M), negative behavior (S) }\end{array}$ \\
\hline \multicolumn{4}{|l|}{ Attachment skills program } \\
\hline Akbarzadeh et al., 2016 & 190 mothers, universal & Routine care & Anxiety (?), infant crying (?) \\
\hline \multicolumn{4}{|l|}{ HUGS } \\
\hline Milgrom et al., 2006 & 22 mothers, targeted & No control group & Parenting stress (?) \\
\hline Milgrom and Holt, 2014 & 100 mothers, targeted & Attention placebo & N/A \\
\hline Holt et al., 2021 & 77 mothers, targeted & Attention placebo & Affection involvement and verbalisation (L), bonding (M) \\
\hline \multicolumn{4}{|c|}{ Parental Reflective Functioning based interventions } \\
\hline \multicolumn{4}{|c|}{ Families First } \\
\hline Kalland et al., 2016 & N/A & N/A & N/A \\
\hline \multicolumn{4}{|c|}{ PEEP Reflective Parenting Program } \\
\hline Maskell-Graham, 2014 & 10 mothers, targeted & No control group & Reflective functioning (?), mother-baby interaction (?) \\
\hline \multicolumn{4}{|c|}{ Lighthouse Parenting Program } \\
\hline Byrne et al., 2018 & 16 parents, targeted & No control group & Parental self-efficacy (L) \\
\hline \multicolumn{4}{|l|}{ Circle of Security } \\
\hline Hoffman et al., 2006 & 65 mother-infant dyads, universal & No control group & Attachment style (?) \\
\hline Cassidy et al., 2010 & 20 mother-infant dyads, targeted & No control group & Depressive symptoms (L) \\
\hline Cassidy et al., 2011 & 220 mother-infant dyads, targeted & Psychoeducation sessions & Attachment style among highly irritable infants (?) \\
\hline Kohlhoff et al., 2016 & 15 mother-infant dyads, universal & No control group & $\begin{array}{l}\text { Reflective functioning }(M) \text {, caregiving helplessness }(L) \text {, maternal rejection and anger }(M) \text {, maternal } \\
\text { stress }(M)\end{array}$ \\
\hline Yaholkoski et al., 2016 & 10 studies, universal and targeted & $\begin{array}{l}\text { Meta-analysis, various control } \\
\text { groups }\end{array}$ & Child attachment security $(\mathrm{M})$, caregiving quality $(\mathrm{M})$ \\
\hline Rose et al., 2018 & 9 parents, universal & No control group & Self-efficacy (M) \\
\hline Mothander et al., 2018 & 52 parent-infant dyads, targeted & Treatment as usual & Caregiver perceptions (?), emotionally available interactions (?) \\
\hline \multicolumn{4}{|l|}{ Minding the Baby } \\
\hline Slade et al., 2005b & N/A & N/A & N/A \\
\hline Sadler et al., 2013 & 105 mothers, targeted & Routine care & Infant attachment (?) \\
\hline Slade et al., 2020 & 164 mothers, targeted & Treatment as usual & Maternal reflective functioning (?), infant attachment (?) \\
\hline
\end{tabular}




\section{Interventions targeting child wellbeing}

Families in Mind

$\begin{array}{lll}\text { Bayer et al., 2010a } & 733 \text { families, universal } & \text { Usual primary care } \\ \text { Hiscock et al., 2012 } & \text { N/A } & \text { N/A }\end{array}$

Tuning in to Toddlers

Lauw et al., 2014

34 mother-toddler dyads, universal

No control group

Havighurst et al., 2019

N/A

Relationships for Growth and Learning

$$
\text { Bekar et al., } 2017 \quad 47 \text { children, targeted }
$$

Early Head Start

$$
\text { Administration for } \quad 3000 \text { families, targeted }
$$

N/A

Families, 2001

$$
\begin{array}{ll}
\text { Raikes and Love, 2002 } & \text { N/A } \\
\text { Love et al., 2005 } & 3001 \text { families, targeted }
\end{array}
$$

Responsive Early Childhood Curriculum
Landry et al., 2014

\section{Interventions targeting parent mental health, the couple relationship and child wellbeing}

\section{Family Foundations}$$
008
$$

Feinberg et al., 2014

Jones et al., 2018a

169 couples, universa 399 couples, universa

Baby Triple P

Tsivos et al., 2015

Popp et al., 2019

What Were We Thinking

Fisher et al., 2010

Fisher et al., 2016
27 mothers, targeted

49 couples, universal

399 couples, universa

400 couples, univers
No-treatment control

Sent information in post Sent information in post

Treatment as usual

Care as usual

Usual primary health care Usual care
Maternal unreasonable expectations (?)

$\mathrm{N} / \mathrm{A}$

Emotion coaching beliefs (M), emotion coaching behaviors (L), observed emotion coaching (L) emotion labels (L), emotion exploration (L), emotion-dismissing beliefs (L), emotion-dismissing behaviors (L), observed emotion dismissing (M), toddler behavior problems (S)

N/A

Social competence (?), behavioral problems (?)

Cognitive and language development (?), problem behaviors (?), parent support (?), family support (?), parenting stress (?)

$\mathrm{N} / \mathrm{A}$

Cognitive and language functioning (S), aggressive behaviors (S), emotional engagement (S) sustained attention (S), parent-child interactions (S)

Expressive emotion understanding $(M)$, receptive emotion understanding $(S)$, situational emotions task (M), social competence $(M)$, anger and aggression (M)

Coparental support (M), parenting-based closeness (M), maternal depression (M), maternal anxiety (M), parent-child dysfunctional interaction (L), infant duration of orienting (S)

Child internalizing problems $(M)$, internalizing problems for boys $(L)$

Triadic relationship quality $(M)$, negative coparenting $(M)$, negative parenting $(M)$, child internalizing problems (S), child night wakings (S)

No significant effects

Infants awake and content $(\mathrm{L})$, inconsolable crying $(\mathrm{L})$

Risk of depression, anxiety or adjustment disorder for mothers with a psychiatric history (?) Self-rated health (?) 
for participation in the interventions, which included: symptoms of anxiety and depression, low income or socioeconomic status, risk of intimate partner violence, a history of trauma, being in a psychologically vulnerable situation, being an adolescent or young mother, being in jail and having relationship problems.

The existing interventions also included universal programs (Family Foundations, Towards Parenthood, What Were We Thinking, Families First, Boot Camp for New Dads, Families in Mind, Tuning into Toddlers and an unnamed attachment skills program) and programs that could be delivered as either targeted or universal (Baby Triple P, Couple CARE for Parents, Mothers and Babies and Circle of Security). Some of the programs were specifically designed for use with couples (Family Foundations, What Were We Thinking and Couple CARE for Parents) while only one of the programs was developed especially for fathers (Boot Camp for New Dads). Many of the programs enabled partners to be involved, but did not have this as a main focus of the intervention. We present an overview of each of the programs below.

\section{EXISTING EARLY LIFE INTERVENTIONS FOR PARENTS}

\section{Interventions That Target Maternal Mental Health}

The Mindful Motherhood intervention uses aspects of mindfulness based cognitive therapy and acceptance and commitment therapy, with the goal of reducing the risk of adverse maternal mental health outcomes during the perinatal period (Vieten and Astin, 2008). The program is targeted for women who have had low mood during pregnancy. The content is presented in group settings; a clinical psychologist and yoga instructor jointly facilitate these $2 \mathrm{~h}$ sessions once weekly for 8 weeks. The sessions include discussions, provision of information and activities, such as body scan exercises and mindful movement. The mothers are also given guided meditations that they can do every day at home (Vieten and Astin, 2008).

The intervention women showed significant decreases in anxiety $(d=0.89)$ and negative affect $(d=0.83)$ compared to control group women. Improvements were also observed in depression, positive affect, mindfulness, affect regulation and stress; however, these changes were not significant (Vieten and Astin, 2008).

The ROSE Program (Zlotnick et al., 2001) is targeted for women who are on public assistance and at risk of postnatal depression. It uses interpersonal therapy to support the transition to motherhood and build support networks. The program includes content on managing the role transition to becoming a mother, goal setting, interpersonal conflict resolution and developing social supports. The content is presented through four 1-h long group sessions, run weekly.

A pilot study of the program found that intervention group women displayed a significantly greater improvement in depression symptoms as well as being at lower risk of developing postnatal depression (Zlotnick et al., 2001). A larger study found that women who participated in the program were significantly less likely to develop postnatal depression compared to those who did not (Zlotnick et al., 2006). Effect sizes were not provided in these papers. An additional study is currently underway (Johnson et al., 2018).

\section{Interventions That Target Maternal Mental Health and Parenting Skills}

Towards Parenthood is a program for new mothers that targets risk and protective factors for postnatal depression, anxiety and parenting difficulties (Milgrom et al., 2011). There are two parts to the program: a nine unit self-help workbook with telephone support and a community networking component. Eight of the units are antenatal and one is postnatal. The units include: cognitive behavioral strategies, problem solving, reflecting on own life events, building self-esteem, parenting skills and infant bonding. The program addresses partner communication and finding a wider support network. Partners were also able to be involved in the units.

The efficacy of the program has been tested, indicating that the intervention was associated with lower levels of depression $(d=0.6)$, anxiety $(d=0.58)$ and stress $(d=0.59)$ symptoms for mothers. Parenting dysfunction was also lower in the intervention group $(d=0.46)$. Partners in the intervention group also scored lower in depression and anxiety, however, the significance could not be determined due to low numbers of partners who completed the measures.

Practical Resources for Effective Postpartum Parenting (PREPP) is a targeted intervention for women at risk of postnatal depression; it is also focused on optimizing infant behavioral outcomes (Werner et al., 2016). The intervention uses traditional psychotherapy, psychoeducation and mindfulness techniques. It also builds caregiving skills, teaching mothers how to soothe their babies and increase infant sleep using five specific behavioral techniques. The intervention focuses on the mother-infant dyad. Mothers receive three individual sessions with a psychologist, two before birth and one after.

A study found that the intervention resulted in significant reductions in symptoms of depression $(d=0.815)$ and anxiety ( $d=0.664)$, as well as fewer fussing and crying behaviors for babies at 6-weeks postpartum. However, these effects were not sustained at 10 and 16 weeks.

Mothers and Babies is a home visit program targeted for pregnant women who meet low income or other at-risk criteria (Tandon et al., 2018). There are 12 sessions in the program that can be delivered as part of an existing home visit schedule. Mothers and Babies is based on cognitive behavioral therapy and attachment theory. The main cognitive behavioral topics in the program are pleasant activities, thoughts and contact with others. The content is presented through interactive activities. The program has been widely used and tested in a number of studies, displaying efficacy in improving mental health.

The initial study of the program found a small $(h=0.28)$ but insignificant difference in depressive symptoms favoring the intervention group (Munoz et al., 2007). Other studies have found improvements in depressive symptoms at 3-months 
(partial eta squared $=0.01)$ and 6-months $(d=0.73)$ followup (Tandon et al., 2011, 2014). Another study found significant improvements in mood regulation as a result of the program (Mendelson et al., 2013).

A study targeting low income mothers found a post intervention decrease in depressive symptoms $(d=0.38)$ and stress $(d=0.35)$ that was greater than that of the control group; however, this was not maintained at 6-months follow up (McFarlane et al., 2017). The most recent study testing an adapted version of the program (Tandon et al., 2018) found significant effects on depression $(d=0.444)$ and anxiety $(d=0.175)$ at 6 -months follow-up for intervention group mothers. Effect sizes were not included but were calculated from the information provided.

The program has also been run in a clinic as opposed to a home visiting format (Leis et al., 2015). A pilot study using this format with an intervention only group found significant improvements in depressive symptoms $(E S=0.78)$ and $\operatorname{mood}$ regulation $(E S=0.84)$ after the intervention. Another study using the group clinic format found that levels of depression did not differ between the intervention and control groups (Le et al., 2011).

The CAPEDP intervention is a home visiting program that targets the mental health of infants within families living in vulnerable situations (Saias et al., 2013). Other target outcomes include reduced maternal depression and improved family environment. The program is extensive, involving 44 home visits beginning in the third trimester and ending around the child's second birthday. Trained psychologists conduct the visits, which are all manualised. The intervention uses video footage of the mother and her baby, which is discussed with the psychologist. Other features include short films on maternity topics, information on community support services, and assistance in developing parenting skills (Dugravier et al., 2013; Saias et al., 2013).

A randomized controlled trial of the program did not find an overall effect on maternal depressive symptoms, but did find effects on subgroups within the study (Dugravier et al., 2013). The intervention was able to reduce depression for women who had lower baseline levels of depression, were planning to bring up their child with the child's father and who had completed more than 9 years of education. There was not enough data reported to calculate effect sizes.

An antenatal group program was developed focusing on behavioral self-care strategies, psychoeducation for managing mental health, interpersonal therapy and the parent-infant relationship (Thomas et al., 2014). It is targeted for women who have current symptoms of depression or anxiety or are at-risk due to other factors. Women attend six sessions of the program, with a 2-h session each fortnight. Partners are able to attend two of these sessions. The delivery of the program is based on elements of cognitive-behavioral therapy and parent-infant interventions. Mothers and their partners are provided with information and strategies, covering topics such as bonding with infants, responsive parenting, engaging in self-care, contingency planning for emerging mental health problems, and recognizing mental health warning signs in each other (Thomas et al., 2014).
In a targeted pilot study, women who completed the program displayed significant decreases in depression $(d=1.1)$ and anxiety $(d=0.7)$, as well as increases in maternal attachment $(d=0.5)$. Of partners who attended the sessions, $81 \%$ indicated that their understanding of mental health issues had improved (Thomas et al., 2014).

\section{Interventions That Target Fathers}

Boot Camp for New Dads (Capuozzo et al., 2010) appears to be one of the only interventions targeted specifically for new fathers. Fathers learn how to prepare for their baby, support their partner and bond with their baby. The program is run in groups, with both "rookie" fathers and "veteran" fathers, as well as a group coach. "Rookie" fathers attend one session before birth and are invited back after birth to share their new experiences as "veteran" fathers.

The majority of fathers who participated in the program reported increased confidence across multiple areas (Miller, 2012), such as: caring for their baby (92\%), dealing with crying $(90 \%)$, bonding (78\%), understanding their partner's emotions (89\%), supporting their partner (89\%), protecting their family from negative outside influences $(84 \%)$, creating a safe environment for their baby (77\%), developing their own style with the baby $(82 \%)$ and forming a parenting team with their partner (89\%). Qualitative research has also been conducted; however, no randomized controlled trials have been run to test the program's outcomes (Miller, 2012).

\section{Interventions That Target the Couple Relationship Only}

Couple CARE for Parents (Petch et al., 2012) focuses on preparing couples for the transition to parenthood by enhancing their couple relationship and building mutual support. It aims to promote communication between parents, especially with regards to parenting. The program includes content on mental health and self-care, such as: education about how to prevent, detect and seek help for perinatal depression and anxiety, mindfulness, breaking the spiral of depression, CBT and selfmonitoring. The program is delivered over six units - one group session, two home visits and three phone calls. Trained facilitators walk through the program with couples and guide them through the various topics.

The program has been able to decrease negative couple communication at post-test, specifically conflict (females, $r=0.84$; males, $r=0.92$ ), invalidation (females, $r=0.82$; males, $r=0.86$ ) and negative affect (females, $r=0.84$; males, $r=0.92$ ), these being large effects (Halford et al., 2010). Smaller effects were found for women's relationship adjustment $(r=0.32)$ and self-regulation $(r=0.46)$ at 12 -months postpartum. Effects were not found for parenting stress. In another study, the program reduced conflict $(d=0.38)$ and invalidation $(d=0.44)$ in women (Petch et al., 2012). It also prevented deterioration in relationship satisfaction for high risk women but displayed no effects for men. The program did not appear to have an impact on intimate partner violence or relationship problems (Heyman et al., 2019). 


\section{Interventions That Target the Mother-Infant Relationship}

The Adolescent Mothers' Program: Let's meet your baby as a person is a targeted program for adolescents mothers (AMPLE; Nicolson et al., 2013). The intervention focuses on the mother-infant relationship and is run across two sessions, in addition to regular maternity care. The first of these is a group session where mothers watch and discuss video clips about connecting with their newborn. The second session is individual, and each mother talks through getting to know her own baby. Although the main focus is building attachment between the mother and baby, partners are also able to attend.

A study found significant effects on some aspects of emotional availability, including maternal non-intrusiveness $(d=1.06)$ and maternal non-hostility $(d=0.66)$ in a play only task and maternal non-intrusiveness $(d=0.85)$ and maternal non-hostility $(d=0.66)$ in a play plus separation-reunion task (Nicolson et al., 2013). Effects were non-significant for maternal sensitivity and structuring, or child responsiveness and involvement.

The Mom Power program aims to build secure attachment between mothers and their babies, using a delivery method of psychoeducation and skills training (Muzik et al., 2016). The program is particularly designed for mothers who have previously experienced or are currently experiencing trauma (Rosenblum et al., 2018). A major goal of the intervention is to encourage sensitive parenting through skills practice and reflection. Mothers are also provided with opportunities to acquire self-care skills and social support. The intervention consists of 10 group sessions and 3 individual sessions, led by two trained facilitators. Each group session, to which mothers can bring all of their children less than 6 years old, begins with a shared meal. During the rest of the session, mothers work through the manualised program, while children take part in a separate play-based session (Muzik et al., 2015). To complete the session, mothers and children take part in a fun activity together.

Intervention only studies have been conducted, comparing completers and non-completers of the program (Muzik et al., 2015, 2016). Results indicate that the program is able to contribute to decreases in depressive symptoms, PTSD symptoms, maternal helplessness and clinical diagnoses (Muzik et al., 2015, 2016). As these studies did not have control groups, subsequent studies used randomized controlled trials to test for efficacy.

A study involving high-risk mothers (Rosenblum et al., 2017) found that women in the intervention group decreased significantly in PTSD symptoms $(d=0.342)$ and parenting stress $(d=0.334)$; however, the opposite effect was seen in that control group women decreased significantly in depressive symptoms, while the intervention group $\operatorname{did} \operatorname{not}(d=0.233)$. Among women with a history of intimate partner violence, strong effects were found for the intervention group in decreased symptoms of depression $(d=0.462)$ and PTSD $(d=0.401)$. Another study found an increase in reflective parenting $(d=0.296)$ for the intervention but not the control group (Rosenblum et al., 2018).
Playing and Learning Strategies (PALS) is a ten-week home visiting program that targets maternal responsiveness in order to enhance infant outcomes (Landry et al., 2006). It is targeted especially for mothers from a low income background or for infants with low birth weight, and emphasizes taking the family context into account. Reflecting on videotaped mother-baby interactions is a major component of the intervention. Each week, the facilitator coaches the mother through a new target behavior, and films the mother interacting with her baby. They also spend time discussing the videotaped interaction from the previous week, and plan how to incorporate the target behaviors into daily life. Mothers learn how to observe the responses of their infants. The toddler program (Landry et al., 2008) builds upon the infant program, continuing to teach mothers responsive behaviors through coaching and reflection on videotaped interactions.

The program has demonstrated increases in aspects of maternal responsive behaviors (Landry et al., 2006), including contingent responsiveness $(d=0.85)$, support of infant foci of attention $(d=0.65)$, verbal scaffolding $(d=0.79)$ and object labeling $(d=0.71)$. However, an iatrogenic effect was found among high-risk mothers, with the control group mothers displaying higher levels of smiling and laughing than intervention group mothers $(d=0.55)$. Effects were also seen in infants, including significantly increased early communication $(d=0.75)$ and social cooperation $(d=0.50)$ with their mothers. A subsequent study (Landry et al., 2008) examined the effects of further intervention at the toddler stage. Intervention at the toddler stage was linked to significant effects on verbal encouragement $(d=0.25)$, child cooperation $(d=0.30)$ and child social engagement $(d=0.32)$. Mothers and toddlers who participated in the intervention at both stages had higher levels of contingent responsiveness $(d=0.51)$ and more decreases in negative behavior $(d=0.16)$.

A universal attachment skills program was developed to target infant mental health through building mother-infant attachment (Akbarzadeh et al., 2016). The program consists of four sessions, run once weekly for 60-90 min, with session content delivered through discussions, time for questions, lecture-style provision of information, videos and role-plays. The sessions have a large focus on attachment behaviors, with mothers also learning about the physiology of pregnancy, awareness of their embryo's feelings, and maintaining good health during pregnancy.

At the time of birth, mothers in the control group scored significantly higher in anxiety, while babies in the intervention group had significantly less crying. However, baseline data for mothers was not collected prior to the intervention being run (Akbarzadeh et al., 2016).

HUGS (Milgrom and Holt, 2014) is an intervention targeted for women with a diagnosis of postnatal depression. The four week program includes education and activities that address mother-infant interaction; mothers are given opportunities to interact with their infants while learning practical skills such as recognizing infant cues. The HUGS program is designed to be run in conjunction with cognitive behavioral therapy for postnatal depression.

A pilot study of a previous three week version of the program found a decrease in parenting stress among women 
who participated. However, there was no control group. A subsequent study combining the HUGS intervention with a nine week cognitive behavioral program explored the effects on the mother-infant relationship, maternal mood and infant wellbeing (Milgrom and Holt, 2014). Preliminary results indicate improvements in affective involvement and verbalisation (partial eta squared $=0.10$ ) and bonding ( partial eta squared $=0.09$ ) for the intervention group mothers. Results were not found for parenting stress or infant outcomes (Holt et al., 2021).

\section{Mentalization Based Interventions That Target Parental Reflective Functioning}

Families First is a parenting group program that has a unique focus on parental reflective functioning (Kalland et al., 2016). It aims to improve parent-child attachment through building mentalization capacity. It focuses on the whole family and also teaches parents to develop a wider social support network. The program was designed to reduce parenting stress and depression. The groups are offered for first time parents whose babies are 34 months old. There are twelve sessions in the program, with each running for approximately $2 \mathrm{~h}$. To date, there have been no results published on the efficacy of the program.

The PEEP Reflective Parenting Program is designed for expectant parents and is delivered during the perinatal period (Maskell-Graham, 2014). The program aims to build parental reflective functioning capacity and develop secure attachments between parents and babies. Parents are encouraged to view their babies as individuals with their own internal thoughts and feelings. Another goal of the program is to build support networks for parents within the community. The content is delivered through a home visit and seven group sessions. Preliminary results indicated improvements in reflective functioning and mother-baby interaction, but not in anxiety and parenting stress. However, the data was not analyzed statistically so the significance and size of effects could not be determined (Maskell-Graham, 2014).

The Lighthouse Parenting Program is a 20-week MentalizationBased Treatment (MBT) designed for high-risk parents of infants aged 0-2 years (Byrne et al., 2018). This intervention is designed to increase sensitive parenting and prevent child maltreatment through increasing parents' capacity to mentalize their child's internal states. The program involves weekly group sessions and fortnightly individual sessions for parents; children are not included in the intervention.

The program displayed a significant effect on parental selfefficacy $(d=1.675)$ for mothers. Non-significant improvements were seen in parental stress, parental sensitivity, anxiety, depression, parental mentalizing and global distress. The low levels of depression and anxiety reported at baseline, as well as the small sample size could have impacted the significance of findings.

The Circle of Security (COS) intervention aims to increase parental sensitivity in order to promote the development of secure attachment in children (Kohlhoff et al., 2016). Initially, COS was designed as a 20-session weekly group-intervention intended to enhance parental ability to interpret child cues
(Yaholkoski et al., 2016), however, a shorter 8-session version (COS-P) has also been created, with the same key components and aims as the original version (Cooper et al., 2009). Both the original and the shortened versions include an overview of attachment theory as well as videos designed to demonstrate secure and problematic parent-child interactions; however, unlike COS-P, where pre-recorded footage is used, the original version includes videos of participants and their own children filmed in the strange situation (Kohlhoff et al., 2016).

The COS program has been researched extensively since its development. A study involving women in a jail diversion program found that depressive symptoms were significantly lower after the intervention $(E S=0.88)$, yet the rates of attachment security and maternal sensitivity did not differ from those in the population (Cassidy et al., 2010). Another study found significant decreases in disorganized and insecure attachment (Hoffman et al., 2006). A pilot version of the shorter version of the program found favorable effects on reflective functioning $(E S=0.59)$, caregiving helplessness $(E S=0.73)$, maternal rejection and anger $(E S=0.48)$, and maternal stress $(E S=0.48)$ (Kohlhoff et al., 2016). Effects have also been found on aspects of self-efficacy ( $E S=0.55$ ) (Rose et al., 2018). However, all of these studies used a one-group pretest posttest design and thus did not have a control group, so it is difficult to determine whether or not these findings reflect intervention effects.

The program has also been studied using randomized controlled trials. In a targeted study for economically stressed mothers, effects were not found for the overall sample, however, among highly irritable infants, intervention group children were more likely to be securely attached after the intervention, as compared to the control group (Cassidy et al., 2011). A study of the shortened version found significant increases in balanced caregiver perceptions and emotionally available interactions in the intervention group but not the control group (Mothander et al., 2018).

A meta-analysis has been conducted on the program, although it must be noted that this included data from sources not within the scope of this review, such as unpublished data and articles, and COS as a program for children older than 3 years old (Yaholkoski et al., 2016). The analysis found significant, medium effects on both child attachment security $(g=0.65)$ and caregiving quality $(g=0.60)$.

The Minding the Baby (MTB) attachment-based intervention aims to promote secure attachment in infants through increasing maternal reflective functioning in vulnerable young primiparous mothers (Sadler et al., 2013). Beginning in the second trimester of pregnancy, this intensive program endeavors to improve developmental, health and relationship outcomes for participating families (Slade et al., 2020). Families receive weekly alternating visits by a nurse and a social worker for the first year of the child's life, followed by bi-weekly visits until the child reaches age 2 (Slade et al., 2020). Other family members including the child's father are encouraged to participate, however, the mother and child remain the focus of this intervention (Slade et al., 2020).

In a study of young mothers, results indicated a significantly higher percentage of secure infant attachment in the intervention 
group and significantly lower disorganized attachment. There were no significant effects found for maternal mental health or reflective functioning, although there were effects on subgroups within the sample (Sadler et al., 2013). There was a nonsignificant trend toward less referrals to the Child Protective Services at 24-months follow-up. Another study found significant effects on maternal reflective functioning and infant secure attachment, but not on affective communication or maternal mental health (Slade et al., 2020).

\section{EXISTING EARLY LIFE INTERVENTIONS FOR CHILDREN}

\section{Interventions That Target Child Wellbeing}

Families in Mind (Hiscock et al., 2012) is a combination of two interventions - Toddlers Without Tears and the Family Check-Up. The Toddlers Without Tears program is universal and targets negative parenting styles and child mental health (Bayer et al., 2010a). It is delivered through a combination of one individual session and two group sessions. The parents learn strategies for managing behavior in their toddlers. A study has found that this program alone does not appear to be enough to prevent emotional and behavioral problems in children or mental health problems in mothers. The only effect demonstrated was on mothers' unreasonable expectations of their toddlers, which were significantly lower in the intervention group (Bayer et al., 2010a). Not enough information was provided to calculate effect sizes. The Family Check-Up is targeted and has previously displayed efficacy when delivered to disadvantaged families. In this program, families receive one-on-one home visits from a psychologist. A longitudinal study of the Families in Mind program has commenced and is still in progress.

Tuning into Toddlers (TOTS) is a universal program designed to enhance emotional development in toddlers through addressing their parents' emotion socialization and emotion regulation (Havighurst et al., 2019). It is also based on the theories of attachment, mindfulness and neurobiology. In particular, TOTS aims to build emotional coaching skills in parents, as this is a major protective factor for child mental health. The program is run across six weekly sessions, each of which are $2 \mathrm{~h}$ long (Lauw et al., 2014). Parents learn the five steps of emotional coaching, for example, being aware of children's emotions and helping label emotions. They learn information about toddler needs and development. The program is manualised and is presented to groups using discussions, role-plays, psychoeducation and other activities.

A pilot study of the program (Lauw et al., 2014) found a number of effects, including increased emotion coaching beliefs ( $d=0.50)$, emotion coaching behaviors $(d=1.38)$, observed emotion coaching $(d=0.92)$, emotion labels $(d=0.87)$ and emotion exploration $(d=0.68)$. There were also significant decreases in emotion-dismissing beliefs $(d=0.70)$, emotiondismissing behaviors $(d=0.80)$, observed emotion dismissing $(d=0.49)$ and toddler behavior problems $(d=0.30)$. As the pilot study used a small intervention only design, another study using a randomized controlled trial design is currently underway (Havighurst et al., 2019).

The Relationships for Growth and Learning Program is designed to target preschool children who are at risk for developing mental health problems (Bekar et al., 2017). The program uses peer play psychotherapy and other mental health services. While the program is essentially child-focused, parents and teachers are also involved, as the program uses a whole system approach. The program was run in childcare centers for children at clinical risk due to internalizing and externalizing symptoms, environmental risk and challenging histories. The children received peer play therapy in groups with a trained therapist. Individual sessions were also given if necessary.

The clinical children increased significantly in social competence and decreased in total problems and behavioral problems. After participation in the program, the clinical group of children had caught up to the nonclinical group of children in behavioral functioning in that they no longer had more total problems, including behavioral, internalizing, externalizing and other problems.

Early Head Start (Raikes and Love, 2002) refers to a range of programs for low-income pregnant women and their families, which can be based at the family home or in the community. The programs involves two generations and follows children over the first few years of life.

A large study of the Early Head Start programs, which included data from 3,001 families across 17 programs, measured the efficacy of the programs when children were 2 and 3 years of age (Love et al., 2005). Families within each of the 17 programs were randomly assigned to an intervention or control group. When children were 2 years of age, the results indicated decreased risk for intervention group children in a number of areas, including children's cognitive and language development (14.9\%), problem behaviors (10.2\%), parental support (13.5\%), parenting stress (11\%) and family support in the home environment (11.5\%), as compared to the control group children (Administration for Children, Youth and Families, 2001).

At 3 years old, children who were part of the interventions had better cognitive and language functioning $(d=0.12)$, fewer aggressive behaviors $(d=0.11)$ and higher emotional engagement $(d=0.20)$ and sustained attention $(d=0.16)$ with their parents, compared to children in the control group. Parents also displayed better interactions with their children $(d=0.11)$. An analysis of program type revealed that programs that were both home and community based had the most desirable results for children $(d=0.23-0.31)$ and parents $(d=0.21-0.28)$.

The Responsive Early Childhood Curriculum (RECC; Landry et al., 2014) was developed for toddlers from low income backgrounds in childcare centers, with the goal of enhancing the quality of care received during the formative years. The program involved equipping teachers with the ability to engage in responsive teacher-child interactions. Teachers were trained and implemented the curriculum in their centers.

A randomized study was conducted, with two intervention groups and one control group. One intervention group used the regular RECC and the enhanced intervention group used the RECC plus extra activities to build social emotional 
skills. Children in the intervention groups scored higher than control group children in expressive emotion understanding $(d=0.47)$, receptive emotion understanding $(d=0.25)$ and a situational emotions task $(d=0.44)$. Control group children displayed a significant rise in anxiety, but intervention group children did not. Children in the regular $(d=0.42)$ and enhanced $(d=0.39)$ intervention groups increased in social competence at some, but not all time points. Children in the regular intervention group decreased significantly in anger and aggression compared to the control group $(d=0.55)$.

\section{Interventions That Target Parent Mental Health, the Couple Relationship and Child Wellbeing}

Family Foundations is a universal program for expectant couples which focuses on enhancing co-parenting and mental health (Feinberg and Kan, 2008). It was developed based on extensive research on the importance of co-parenting, including the dimensions of co-parental support and parenting-based closeness. The program is psychoeducational and teaches skills such as teamwork, conflict management and communication. It has eight sessions throughout the perinatal period and is run in groups. The program has been tested in multiple studies, revealing promising effects for mothers, fathers and children. Outcomes include: decreased depression and anxiety for mothers, higher co-parenting support for both parents, higher parenting-related closeness for fathers, more adaptive duration of orienting and soothability for infants, better relationship quality for parents and less child internalizing problems up to 7 years later (Feinberg and Kan, 2008; Feinberg et al., 2014; Jones et al., 2018a).

The initial study (Feinberg and Kan, 2008) found significant effects on coparental support (mother report, $d=0.35$; father report, $d=0.54$ ), father reported parenting-based closeness $(d=0.44)$, maternal depression $(d=0.56)$, maternal anxiety $(d=0.38)$, father reported parent-child dysfunctional interaction $(d=0.70)$, and infant duration of orienting $(d=0.34)$. Effects were not found for paternal mental health or coparental undermining. The follow-up study (Feinberg et al., 2014) found that 6 years later there were significant effects on teacher reported internalizing problems $(d=0.55)$ and boys' externalizing problems $(d=0.75)$, but no effects for parent reported outcomes. Another larger study of the program (Jones et al., 2018a) found significant effects at 2-year follow-up on triadic relationship quality $(d=0.39)$, negative coparenting $(d=0.38)$, negative parenting $(d=0.41)$, child internalizing problems $(d=0.19)$ and child night wakings $(d=0.30)$.

Baby Triple $P$ (Tsivos et al., 2015) is a targeted program for mothers with postnatal depression that uses parenting education. The content includes: infant care strategies, parent coping skills, catching unpleasant thoughts and emotions, breathing, positive self-talk, partner and social support, parenting routines, communication, transition to parenthood and goal setting. There are eight sessions and homework tasks to complete between sessions.
A study including women who had been diagnosed with postnatal depression did not find any significant differences in parent or child outcomes as a result of the intervention (Tsivos et al., 2015). However, the program displayed high acceptability levels with participants. Another study of the program (Popp et al., 2019) took a universal approach and included both mothers and fathers in the program. The study found that babies in the intervention group were more frequently awake and content ( $d=0.88)$ and had less inconsolable crying $(d=0.85)$ than those in the control group. Effects were not found for infant behavioral problems or parental outcomes.

What Were We Thinking is a universal psychoeducational program for couples and their babies (Fisher et al., 2010). It is delivered in a group setting through one session after birth, with additional take-home materials. The aim of the program is to prevent depressive and anxiety disorders. The program addresses caring for the baby, managing infant crying, and having a healthy mother and father relationship.

A study found effects for the intervention on mental health, but only among mothers with no psychiatric history (Fisher et al., 2010). For these mothers, the intervention was associated with a significantly lower risk of being diagnosed with depression, anxiety or adjustment disorder, the relative risk reduction being $48 \%$. In a later study, the intervention has also displayed effects on self-rated health (Fisher et al., 2016). No effects have been found for unsettled infant behaviors, mother-baby relationship quality or partner relationship satisfaction (Fisher et al., 2016).

\section{DISCUSSION}

In this review, we found a total of 27 interventions for infants and young children aged $0-3$ and their parents, with these spanning a wide range of approaches and target outcomes. Programs were universal or targeted, with some being delivered as both across different studies (Tsivos et al., 2015; Popp et al., 2019). Interventions were focused on outcomes such as maternal mental health, parenting skills, coparenting, parentinfant attachment, reflective functioning, child wellbeing and the couple relationship. Some programs focused on multiple outcomes. The programs also differed in the approaches they used, with these including cognitive behavioral therapy, mentalization based therapy, psychoeducation, practical skills training, and mindfulness.

McLuckie et al. (2019) conducted a scoping review of mental health programs for $0-5$ year old children, exploring the overall view of existing interventions, including a broad summary of therapeutic mechanisms, outcome measures, geographical location, research designs, levels of intervention and target populations. The researchers found that the largest proportion of programs were selective, while there were far lower numbers of universal programs. The most common approaches utilized were parenting education groups, interventions targeting the parentchild dyadic relationship and home visits (McLuckie et al., 2019).

We took a similar approach in this review, although we focused on a more specific age group and explored the content of individual programs. In our review, we focused on the $0-3$ age 
group, as this is a critical time of development in which early influences can greatly shape a child's future trajectory (Zero to Three, 2012; Lyons-Ruth et al., 2017). Following on from the scoping review (McLuckie et al., 2019), we aimed to examine individual programs that currently exist, in order to determine the approaches that have been effective at targeting mental health in this age group.

\section{Universal and Targeted Programs}

Universal and targeted programs have both displayed evidence of efficacy for child and parent outcomes. Targeted programs appear to be particularly effective for maternal mental health outcomes. Programs targeted for mothers at higher risk - such as PREPP, the ROSE Program, Mother and Babies, Mindful Motherhood, Mom Power and the antenatal group program - have demonstrated multiple impacts on mental health outcomes such as symptoms of depression, anxiety and PTSD, risk of a clinical diagnosis, stress, negative affect and mood regulation (Zlotnick et al., 2001; Vieten and Astin, 2008; Thomas et al., 2014; Muzik et al., 2015; Werner et al., 2016; Tandon et al., 2018). Although targeted programs have also demonstrated some effects on other outcomes, the majority of effects appear to be related to maternal mental health.

Universal programs are able to impact maternal mental health outcomes too, yet also appear to have wider effects on other outcomes. A number of universal programs - Family Foundations, Toward Parenthood, What Were We Thinking, and Couple CARE - appear able to influence outcomes across a number of domains, including parental mental health, infant mental health, the parenting relationship, and the parent-child relationship (Feinberg and Kan, 2008; Fisher et al., 2010; Halford et al., 2010; Milgrom et al., 2011). Universal programs have the added advantage that they are able to reach a larger proportion of the population.

Family Foundations, in particular, is a universal program that has demonstrated effectiveness on outcomes for both parents and children. It is one of the programs with the longest term effects, with reduced child internalizing symptoms evident up to 6 years after the program was delivered (Feinberg et al., 2014). The studies on this program have been of high quality, using randomized controlled trials with sample sizes of a few hundred participants.

\section{The Parent-Child Relationship}

Considering the importance of the parent-child relationship that has been highlighted in the literature, we explored the programs that focused enhancing secure attachment and parental reflective functioning. In line with the scoping review of McLuckie et al. (2019), we found that a large proportion of current intervention programs focus on the parent-child relationship.

The AMPLE program was effective at increasing emotional availability for young mothers (Nicolson et al., 2013). Studies on the PALS program have found results for maternal and child behavioral outcomes, especially for high risk women (Landry et al., 2008). The Lighthouse Parenting Program was able to improve parental self-efficacy (Byrne et al., 2018). Minding the Baby has been effective at improving maternal reflective functioning and child attachment (Sadler et al., 2013;
Slade et al., 2020). The HUGS program was able to improve bonding and maternal communication with infants (Holt et al., 2021) and reduce parenting stress (Milgrom et al., 2006).

Mom Power appears to be a promising program which has demonstrated efficacy for maternal mental health symptoms and other outcomes across four studies, two of which were randomized controlled trials (Rosenblum et al., 2018). A large number of studies have been conducted on the Circle of Security intervention. Many of these were intervention only studies, which makes it difficult to determine if results were due to the intervention (Rose et al., 2018). However, randomized controlled trials of the program have also indicated that it is effective in improving parenting and child attachment (Cassidy et al., 2011; Mothander et al., 2018).

The PEEP program, Families First, and the universal attachment skills program also focused on building the parentchild relationship. However, the efficacy of these programs is hard to determine. Families First does not yet have any published data, and the data for the PEEP program and the universal attachment skills program was not analyzed in a way that enabled statistical conclusions to be drawn.

Considering that attachment and reflective functioning based programs have demonstrated some effects for parents and their children, it appears that targeting aspects of the parent-child relationship is an important feature to include in interventions. It is worth noting that the research on Mom Power, AMPLE, PALS, Minding the Baby, HUGS and the Lighthouse Parenting Program has been on targeted samples, while Circle of Security has been trialed as both a universal and targeted program. The majority of these studies only involved mothers, rather than both parents. In future studies, it would be beneficial to explore the effects of attachment and reflective functioning programs on universal samples, and on targeted samples which include both parents, as this is a gap in the literature.

\section{The Parent Couple Relationship}

As well as the parent-child relationship, the relationship between parents has also been identified in the literature as an important factor for child mental wellbeing. Programs that specifically targeted the parenting relationship were Couple CARE for Parents, Family Foundations, and What Were We Thinking. Couple CARE has demonstrated a number of effects, particularly on couple communication (Halford et al., 2010). However, some of the program's effects were only found for mothers. Family Foundations has been effective in improving parent mental health, the couple relationship and child outcomes (Feinberg and Kan, 2008; Feinberg et al., 2014). What Were We Thinking has demonstrated mixed results; it is possibly effective at improving mental health outcomes, but does not seem to impact the parenting relationship or infant outcomes (Fisher et al., 2010, 2016). All three of these programs have been tested in universal studies, while Couple CARE has also been run as a targeted intervention.

Baby Triple $\mathrm{P}$ is a program for mothers that has recently been studied when run in a couples format (Popp et al., 2019). Results were found for infant outcomes but not for parenting outcomes. Of the programs targeting the couple relationship 
and coparenting, Family Foundations and Couple CARE for Parents appear to be the most promising (Feinberg and Kan, 2008; Petch et al., 2012). Couple Care for Parents appears effective at improving outcomes related to the relationship between partners, while Family Foundations has demonstrated effects on the parenting relationship and mental health for parents and children. Both of these programs are psychoeducational and involve running through six to eight sessions as a couple with a trained facilitator. They have the advantage of being relatively brief and cost effective to implement.

Four of the programs - Toward Parenthood, the antenatal group program, Families First, and Minding the Baby encouraged partners to attend some of the sessions, but did not have the couple relationship as a specific focus of the intervention. This appears to be a common finding in the literature. A review of partner inclusive interventions found that nine out of thirteen studies addressing the parenting relationship appeared effective in reducing depression and anxiety (Pilkington et al., 2015). However, the majority of these did not actually test the effectiveness for partners, and some did not even involve partners, despite including content on the parenting relationship (Pilkington et al., 2015). Given the consistent evidence of the importance of partner support, this needs to be taken into account when developing future interventions (Pilkington et al., 2015).

\section{The Role of Fathers}

While the programs previously mentioned included both parents, there is a shortage of programs that specifically focus on helping fathers to transition to the parenting role. Programs tend to focus on the mental health of mothers, and do not include fathers and partners (Pilkington et al., 2015; O'Brien et al., 2017). Given the link between the mental health of mothers and partners, and the influence of the father on the infant and young child's development, this is an important gap to address.

Boot Camp for New Dads was the only program reviewed that was designed specifically for fathers, to help them bond with their baby (Capuozzo et al., 2010). It appears that the program was effective, however, the results were not analyzed statistically, so this is difficult to determine with certainty. More research needs to be conducted, especially to investigate the effects of this program on mental health for fathers. Focusing interventions on the mother-child attachment relationship alone is not sufficient, and further research should be conducted on the impact of these interventions on father-child relationships, as well as fathers' mental health.

\section{Programs Aimed at Children}

While the majority of programs involved the parents as participants, the Responsive Early Childhood Curriculum, the Relationships for Growth and Learning Program and Early Head Start focused mainly on children (Love et al., 2005; Landry et al., 2014; Bekar et al., 2017). These programs were targeted for toddlers at risk, due to individual or environmental risk factors. Relationships for Growth and Learning used principles of play psychotherapy and was successful in that it enabled atrisk toddlers to catch-up to their peers in behavioral functioning
(Bekar et al., 2017). Early Head Start has been studied extensively with 3,000 families, with the research finding that it has positive impacts on children's cognitive, behavioral, social and emotional functioning (Love et al., 2005). The Early Head Start programs were most effective when delivered in both home and community settings. The RECC focused on building responsive interactions with toddlers, and found results for social and emotional competence (Landry et al., 2014). It has been studied with a large sample of toddlers.

\section{Qualitative Experiences}

Most of the research we found was quantitative in nature. However, studies would also benefit from collecting qualitative data. Qualitative results can illuminate effects of the program that are missed by quantitative data. For example, the Lighthouse Parenting Program interviewed mothers who participated in the program. Although the program did not achieve all of the expected outcomes, the discourse from mothers emphasize its value to participants. It would be beneficial for future studies to explore qualitative experiences of parents in the program.

\section{CONCLUSION}

Pregnancy and infancy are important developmental periods where the mental wellbeing of both parents and infants needs to be considered in order to prevent the emergence of mental health difficulties during infancy and early childhood. Research has demonstrated that it is possible for infants and children aged from zero to three to develop mental disorders, which must be addressed and treated (Warner and Pottick, 2006). Influences in the early developmental years of a child's life have the capacity to affect them into adulthood. For this reason, there is scope for early interventions during this period to set children up for a positive future life trajectory. Furthermore, rates of parental depression and anxiety during the perinatal period emphasize the need for interventions to address mental health during this time (Woody et al., 2017; Philpott and Corcoran, 2018).

A number of interventions for parents and children have already been researched. The literature suggests that programs that target the parent's mental health and wellbeing, as well as the parent-child and couple relationship have the potential to promote good parent and child mental health. Our findings suggest that mothers, partners and children should all be included for an intervention to be most effective. Parent interventions ideally focus on improving the parents' mental health as well as building protective factors that will benefit their children. As demonstrated in a range of studies already described, interventions for parents and children have the capacity to build protective factors including secure attachment, parental mentalizing capacity and a positive coparenting relationship.

The interventions described above can act as a guide for future intervention efforts during pregnancy and infancy. Programs that were based on cognitive-behavioral principles showed evidence of efficacy (Milgrom et al., 2011; Petch et al., 2012; Tandon et al., 2018). Practical skills training about how to care for the baby 
was another feature of effective programs (Fisher et al., 2010; Werner et al., 2016). A number of programs considered attachment or parent-infant bonding (Capuozzo et al., 2010; Maskell-Graham, 2014; Kalland et al., 2016; Werner et al., 2016; Tandon et al., 2018). Families First and the PEEP Reflective Parenting Program did this through building parental reflective functioning capacity (Maskell-Graham, 2014). The coparenting relationship between parents was another effective component (Feinberg and Kan, 2008; Fisher et al., 2010; Petch et al., 2012), as was the importance of building wider support networks (Zlotnick et al., 2001; Milgrom et al., 2011; Maskell-Graham, 2014; Kalland et al., 2016). Research also suggests that interventions involving children aged zero to three are effective for promoting healthy development. This may be particularly important for infants who come from a high risk background. The interventions for infants described in this review were targeted at high risk infants and displayed evidence of efficacy.

The research evidence suggests that the theoretical backgrounds of interpersonal therapy, cognitive-behavioral therapy, attachment theory and mentalization are ideal starting points for program development. A review of available interventions highlights the need to pull together all of the successful elements of the available interventions and attempt to combine them in an effort to establish an intervention that aims to improve parental mental health and prevent difficulties, support the couple relationship and develop secure parent child relationships which in turn will improve infant mental health. Furthermore, many of the studies, even when aimed to improve child outcomes, did not measure or report these outcomes to evaluate if the intervention indeed had the desired outcome. Future studies should include control groups for the comparison of outcomes. They should also measure the mental health of both parents, attachment style and parental reflective functioning, childhood outcomes and the quality of the couple relationship.

\section{REFERENCES}

Abraham, M., and Kerns, K. (2013). Positive and negative emotions and coping as mediators of mother-child attachment and peer attachment. Merrill Palmer Q. 59, 399-425. doi: 10.1353/mpq.2013.0023

Administration for Children, Youth and Families (2001). Building Their Futures: How Early Head Start Programs are Enhancing the Lives of Infants and Toddlers in Low-Income Families. Summary Report. Office of Research and Evaluation. Washington, DC: Administration for Children, Youth and Families.

Ainsworth, M. D. S., Blehar, M. C., Waters, E., and Wall, S. (1978). Patterns of Attachment: A Psychological Study of the Strange Situation. Oxford: Erlbaum.

Akbarzadeh, M., Dokuhaki, A., Joker, A., Pishva, N., and Zare, N. (2016). Teaching attachment behaviors to pregnant women: a randomized controlled trial of effects on infant mental health from birth to the age of three months. Ann. Saudi Med. 36, 175-183. doi: 10.5144/0256-4947.2016.175

Andrews, G., and Wilkinson, D. D. (2002). The prevention of mental disorders in young people. Med. J. Aust. 177, S97-S100.

Ashford, J., Smit, F., van Lier, P. A. C., Cuijpers, P., and Koot, H. M. (2008). Early risk indicator of internalizing problems in last childhood: a 9-year longitudinal study. J. Child Psychol. Psychiatry 49, 774-780. doi: 10.1111/j.1469-7610.2008. 01889.x

Australian Institute of Health and Welfare (2016). Australian Burden of Disease Study: Impact and Causes of Illness and Death in Australia 2011. Available online at: https://www.aihw.gov.au/reports/burden-of-disease/abds-impact-
In summary, there is great potential to intervene during pregnancy and infancy to improve the mental health of both infants and their parents. Early life mental health difficulties can continue to impact the individual well beyond this time, and thus it is important to develop interventions that can prevent these difficulties. As outlined in this review, several programs have already been developed with this goal in mind. Knowledge of the effective components of these interventions can be used to inform the development of future prevention efforts, with the aim of optimizing mental health outcomes for infants and their families. The mental health team of the ORIGINS Project, in partnership with Telethon Kids Institute, is currently developing a program that addresses these outcomes, with the aim of enhancing prevention efforts during infancy and early childhood. The program will be piloted at a large health campus located in Perth, to assess the efficacy for children and their parents.

\section{AUTHOR CONTRIBUTIONS}

RR conceptualized the scope of the review and was the lead researcher in the project. EI researched the topic and wrote article content. SP is the director of the ORIGINS Project, to which this review belongs; she contributed content to the review. MD and MM researched the topic, wrote article content, and prepared the manuscript. All authors contributed to the article and approved the submitted version.

\section{FUNDING}

This research was funded by the Government of Western Australia Mental Health Commission.

and-causes-of-illness-death-2011/contents/highlights (accessed November 3, 2020).

Balbernie, R. (2013). The importance of secure attachment for infant mental health. J. Health Visit. 1, 210-217. doi: 10.12968/johv.2013.1.4.210

Banker, J. E., and LaCoursiere, D. Y. (2014). Postpartum depression: Risks, protective factors, and the couple's relationship. Issues Mental Health Nurs. 35, 503-508. doi: 10.3109/01612840.2014.888603

Barkham, M., Shapiro, D., Hardy, G., and Rees, A. (1999). Psychotherapy in two-plus-one sessions: outcomes of a randomised controlled trial of cognitivebehavioural and psychodynamic-interpersonal therapy for subsyndromal depression. J. Consult. Clin. Psychol. 67, 201-211.

Barlow, J., Sleed, M., and Midgley, N. (2021). Enhancing parental reflective functioning through early dyadic interventions: a systematic review and metaanalysis. Infant Ment. Health J. 2, 21-34. doi: 10.1002/imhj.21896

Bauer, A., Knapp, M., and Parsonage, M. (2016). Lifetime costs of perinatal anxiety and depression. J. Affect. Disord. 192, 83-90. doi: 10.13140/RG.2.2.15919.74406

Bayer, J., Sanson, A., and Hemphill, S. (2006). Parent influences on early childhood internalizing difficulties. J. Appl. Dev. Psychol. 27, 542-599. doi: 10.1016/j. appdev.2006.08.002

Bayer, J. K., Hiscock, H., Ukoumunne, O., Scalzo, K., and Wake, M. (2010a). Three-year-old outcomes of a brief universal parenting intervention to prevent behaviour problems: Randomised controlled trial. Arch. Dis. Child. 95, 187-192. doi: $10.1136 /$ adc.2009.168302

Bayer, J. K., Hiscock, H., Ukoumunne, O. C., Price, A., and Wake, M. (2008). Early childhood aetiology of mental health problems: a longitudinal population-based 
study. J. Child Psychol. Psychiatry 49, 1166-1174. doi: 10.1111/j.1469-7610.2008. 01943.x

Bayer, J. K., Rapee, R. M., Hiscock, H., Ukoumunne, O. C., Mihalopoulos, C., and Wake, M. (2010b). Translational research to prevent internalising problems early in childhood. Depress. Anxiety 28, 50-57. doi: 10.1002/da.20743

Bayer, J. K., Ukoumunne, O. C., Lucas, N., Wake, M., Scalzo, K., and Nicholson, J. M. (2011). Risk factors for childhood mental health symptoms: national longitudinal study of Australian children. Pediatrics 128, e865-e879. doi: 10. 1542/peds.2011-0491

Bayrampour, H., McDonald, S., and Tough, S. (2015). Risk factors of transient and persistent anxiety during pregnancy. Midwifery 31, 582-589. doi: 10.1016/ j.midw.2015.02.009

Bekar, O., Shahmoon-Shanok, R., Steele, M., Levy, J., deFressine, L., Giuseppone, K., et al. (2017). Effectiveness of school-based mental health playgroups for diagnosable and at-risk preschool children. Am. J. Orthopsychiatry 87, 304-316. doi: $10.1037 /$ ort0000173

Benbassat, N., and Priel, B. (2015). Why is fathers' reflective function important? Psychoanal. Psychol. 32, 1-22. doi: 10.1037/a0038022

Benoit, D. (2004). Infant-parent attachment: definition, types, antecedents, measurement and outcome. Paediatr. Child Health 9, 541-545. doi: 10.1093/ $\mathrm{pch} / 9.8 .541$

Berlin, N. (2008). Tripartite therapy with older children: mutuality in the relationship of a parent-child attachment. J. Child Psychol. 34, 335-363. doi: 10.1080/00754170802472885

Bonds, D. D., and Gondoli, D. M. (2007). Examining the process by which marital adjustment affects maternal warmth: The role of coparenting support as a mediator. J. Fam. Psychol. 21:288. doi: 10.1037/0893-3200.21.2.288

Bor, W., McGee, T. R., and Fagan, A. A. (2004). Early risk factors for adolescent antisocial behaviour: an Australian longitudinal study. Aust. N. Z. J. Psychiatry 38, 365-372. doi: 10.1080/j.1440-1614.2004.01365.x

Bosquet, M., and Egeland, B. (2006). The development and maintenance of anxiety symptoms from infancy through adolescence in a longitudinal sample. Dev. Psychopathol. 18, 517-550.

Bowlby, J. (1969). Attachment and loss: Attachment. New York, NY: Basic Books.

Briggs-Gowan, M., Carter, A. S., Bosson-Heenan, J., Guyer, A. E., and Horwitz, S. M. (2006). Are infant-toddler social-emotional and behavioral problems transient? J. Am. Acad. Child Adolesc. Psychiatry 45, 849-858. doi: 10.1097/ 01.chi.0000220849.48650.59

Buttitta, K. V., Smiley, P. A., Kerr, M. L., Rasmussen, M. L., Querdasi, F. R., and Borelli, J. L. (2019). In a father's mind: paternal reflective functioning, sensitive parenting, and protection against socioeconomic risk. Attach. Hum. Dev. 21, 445-466. doi: 10.1080/14616734.2019.1582596

Byrne, G., Sleed, M., Midgley, N., Fearon, P., Mein, C., Bateman, A., et al. (2018). Lighthouse parenting programme: description and pilot evaluation of mentalization-based treatment to address child maltreatment. Clin. Child Psychol. Psychiatry 24, 680-693. doi: 10.1177/1359104518807741

Cabrera, N. J., Shannon, J. D., and La Taillade, J. J. (2009). Predictors of coparenting in Mexican American families and links to parenting and child social emotional development. Infant Mental Health J. 30, 523-548. doi: 10.1002/imhj.20227

Cameron, E. E., Sedov, I. D., and Tomfohr-Madesn, L. M. (2016). Prevalence of paternal depression in pregnancy and the postpartum: an updated metaanalysis. J. Affect. Disord. 206, 189-203. doi: 10.1016/j.jad.2016.07.044

Camoirano, A. (2017). Mentalizing makes parenting work: a review about parental reflective functioning and clinical interventions to improve it. Front. Psychol. 8:14. doi: 10.3389/fpsyg.2017.00014

Campbell, F., Conti, G., Heckman, J. J., Moon, S. H., Pinto, R., Pungello, E., et al. (2014). Early childhood investments substantially boost adult health. Science 343, 1478-1485. doi: 10.1126/science. 1248429

Capuozzo, R. R., Sheppard, B. S., and Uba, G. (2010). Boot camp for new dads: the importance of infant-father attachment. Young Children 65, 24-28.

Carlson, E. A. (1998). A prospective longitudinal study of attachment disorganisation/disorientation. Child Dev. 69, 1107-1128. doi: 10.1111/j.14678624.1998.tb06163.x

Carlson, E. A., Egeland, B., and Sroufe, L. A. (2009). A prospective investigation of the development of borderline personality symptoms. Dev. Psychopathol. 21, 1311-1334. doi: 10.1017/S0954579409990174

Cassidy, J., Woodhouse, S. S., Sherman, L. J., Stupica, B., and Lejuez, C. W. (2011). Enhancing infant attachment security: an examination of treatment efficacy and differential susceptibility. Dev. Psychopathol. 23, 131-148. doi: 10.1017/ S0954579410000696

Cassidy, J., Ziv, Y., Stupica, B., Sherman, L. J., Butler, H., Karfgin, A., et al. (2010). Enhancing attachment security in the infants of women in a jail-diversion program. Attach. Hum. Dev. 12, 333-353. doi: 10.1080/14616730903416955

Cheng, S., Maeda, T., Tomiwa, K., Yamakawa, N., Koeda, T., Kawai, M., et al. (2009). Contribution of parenting factors to the developmental attainment of 9-month-old infants: Results from the Japan Children's Study. J. Epidemiol. 19, 319-327. doi: 10.2188/jea.JE20081014

Christopher, C., Umemura, T., Mann, T., Jacobvitz, D., and Hazen, N. (2015). Marital quality over the transition to parenthood as a predictor of coparenting. J. Child Fam. Stud. 24, 3636-3651. doi: 10.1007/s10826-015-0172-0

Cicchetti, D., Hetzel, S., Rogosch, F. A., Handley, E. D., and Toth, S. L. (2016). An investigation of child maltreatment and epigenetic mechanisms of mental and physical health risk. Dev. Psychopathol. 28(Pt 2), 1305-1317. doi: 10.1017/ s0954579416000869

Clinton, J., Feller, A., and Williams, R. (2016). The importance of infant mental health. Paediatr. Child Health 21, 239-241. doi: 10.1093/pch/21.5.239

Cook, F., Giallo, R., Hiscock, H., Mensah, F., Sanchez, K., and Reilly, S. (2019). Infant regulation and child mental health concerns: a longitudinal study. Pediatrics 143:e20180977.

Cooke, D., Priddis, L., Luyten, P., Kendall, G., and Cavanagh, R. (2017). Paternal and maternal reflective functioning in the western Australian peel child health study. Infant Ment. Health J. 38, 561-574. doi: 10.1002/imhj.21664

Cooper, G., Hoffman, K., and Powell, B. (2009). Circle of Security Parenting: COS-P Facilitator DVD Manual 5.0. In (Vol. 5). Spokane, WA: Marycliff Institute.

Costello, E. J., Egger, H. L., and Angold, A. (2005). The developmental epidemiology of anxiety disorders: phenomenology, prevalence, and comorbidity. Child Adolesc. Psychiatr. Clin. N. Am. 14, 631-648. doi: 10.1016/j.chc.2005.06.003

Cowan, P. A., and Cowan, C. P. (2002). Interventions as tests of family systems theories: Marital and family relationships in children's development and psychopathology. Devel. Psychopathol. 14, 731-759. doi: 10.1017/ S0954579402004054

Davis, E., Sawyer, M. G., Lo, S. K., Priest, N., and Wake, M. (2010). Socioeconomic risk factors for mental health problems in 4-5-year-old children: Australian population study. Acad. Pediatr. 10, 41-47. doi: 10.1016/j.acap.2009. 08.007

DeGangi, G. A., Breinbauer, C., Roosevelt, J. D., and Porges, S. W. (2000). Prediction of childhood problems at three years in children experiencing disorders of regulation during infancy. Infant Ment. Health J. 21, 156-175. doi: 10.1002/1097-0355(200007)21:3<156::AID-IMHJ2>3.0.CO;2-D

Department of Health and Ageing (2007). National Mental Health Report 2007. Canberra: Commonwealth of Australia.

Dopkins Stright, A., and Neitzel, C. (2003). Beyond parenting: Coparenting and children's classroom adjustment. Int. J. Behav. Devel. 27, 31-40. doi: 10.1080/ 01650250143000580

Doss, B. D., Rhoades, G. K., Stanley, S. M., and Markman, H. J. (2009). The effect of the transition to parenthood on relationship quality: An 8-year prospective study. J. Person. Soc. Psychol. 96, 601-619. doi: 10.1037/a0013969

Dugravier, R., Tubach, F., Saias, T., Guedeney, N., Pasquet, B., Purper-Ouakil, D., et al. (2013). Impact of a manualized multifocal perinatal homevisiting program using psychologists on postnatal depression: the CAPEDP randomized controlled trial. PLoS One 8:e72216. doi: 10.1371/journal.pone. 0072216

Dunst, C. J., Bruder, M. B., and Espe-Sherwindt, M. (2014). Family capacitybuilding in early childhood intervention: Do context and setting matter? Sch. Commun. J. 24, 37-48. doi: 10.1007/978-3-319-28492-7_3

Durtschi, J. A., Soloski, K. L., and Kimmes, J. (2017). The dyadic effects of supportive coparenting and parental stress on relationship quality across the transition to parenthood. J. Marit. Fam. Ther. 43, 308-321. doi: 10.1111/jmft. 12194

Dwyer, S. B., Nicholson, J. M., and Battistutta, D. (2003). Population level assessment of the family risk factors related to the onset or persistence of children's mental health problems. J. Child Psychol. Psychiatry 44, 699-711. doi: 10.1111/1469-7610.00156

Edwards, S. L., Rapee, R. M., and Kennedy, S. (2010). Prediction of anxiety symptoms in preschool-aged children: examination of maternal and paternal 
perspectives. J. Child Psychol. Psychiatry 51, 313-321. doi: 10.1111/j.1469-7610. 2009.02160.x

Egger, H. L., and Angold, A. (2006). Common emotional and behavioral disorders in preschool children: presentation, nosology, and epidemiology. J. Child Psychol. Psychiatry 7, 313-337. doi: 10.1111/j.1469-7610.2006.01618.x

Ensink, K., Borelli, J. L., Roy, J., Normandin, L., Slade, A., and Fonagy, P. (2019). Costs of not getting to know you: lower levels of parental reflective functioning confer risk for maternal insensitivity and insecure infant attachment. Infancy 24, 210-227. doi: 10.1111/infa.12263

Ensink, K., Normandin, L., Plamondon, A., Berthelot, N., and Fonagy, P. (2016). Intergenerational pathways from reflective functioning to infant attachment through parenting. Can. J. Behav. Sci. 48:9. doi: 10.1037/cbs0000030

Ensink, K., Normandin, L., Target, M., Fonagy, P., Sabourin, S., and Berthelot, N. (2015). Mentalization of children and mothers in the context of trauma: An initial study of the validity of the Child Reflective Functioning Scale. Br. J. Devel. Psychol. 33, 203-217. doi: 10.1111/bjdp.12074

Esbjørn, B. H., Pedersen, S. H., Daniel, S. I. F., Hald, H. H., Holm, J. M., and Steele, H. (2013). Anxiety levels in clinically referred children and their parents: examining the unique influence of self-reported attachment styles and interview-based reflective functioning in mothers and fathers. Br. J. Clin. Psychol. 52, 394-407. doi: 10.1111/bjc.12024

Fairbrother, N., Janssen, P., Antony, M. M., Tucker, E., and Young, A. H. (2016). Perinatal anxiety disorder prevalence and incidence. J. Affect. Disord. 200, 148-155. doi: 10.1016/j.jad.2015.12.082

Falah-Hassani, K., Shiri, R., and Dennis, C. (2017). The prevalence of antenatal and postnatal co-morbid anxiety and depression: a meta-analysis. Psychol. Med. 47, 2041-2053. doi: 10.1017/s0033291717000617

Fan, A., Buka, S., Kosik, R., Chen, Y., Wang, S., Su, T., et al. (2014). Association between maternal behavior in infancy and adult mental health: a 30-year prospective study. Compr. Psychiatry 55, 283-289. doi: 10.1016/j.comppsych. 2013.08.024

Fearon, R. P., Bakermans-Kranenburg, M. J., van Ijzendoorn, M. H., Lapsley, A.-M., and Roisman, G. I. (2010). The significance of insecure attachment and disorganization in the development of children's externalizing behavior: a meta-analytic study. Child Dev. 81, 435-456. doi: 10.1111/j.1467-8624.2009. 01405.x

Feinberg, M., Jones, D., Roettger, M., Solmeyer, A., and Hostetler, M. (2014). Longterm follow-up of a randomized trial of family foundations" effects on children's emotional, behavioural, and school adjustment. J. Family Psychol. 28, 821-831. doi: $10.1037 /$ fam0000037

Feinberg, M., and Kan, M. (2008). Establishing family foundations: intervention effects on coparenting, parent/infant well-being, and parent-child relations. J. Family Psychol. 22, 253-263. doi: 10.1037/0893-3200.22.2.253

Feinberg, M. E. (2002). Coparenting and the transition to parenthood: A framework for prevention. Clin. Child Fam. Psychol. Rev. 5, 173-195. doi: 10. 1023/A:1019695015110

Feinberg, M. E., Jones, D. E., Hostetler, M. L., Roettger, M. E., Paul, I. M., and Ehrenthal, D. B. (2016). Couple-focused prevention at the transition to parenthood, a randomized trial: Effects on coparenting, parenting, family violence, and parent and child adjustment. Prevent. Sci. 17, 751-764. doi: 10. 1007/s11121-016-0674-z

Felitti, V. J., Anda, R. F., Nordenberg, D., Williamson, D. F., Spitz, A. M., Edwards, V., et al. (1998). Relationship of childhood abuse and household dysfunction to many of the leading causes of death in adults. Am. J. Prev. Med. 14, 245-258. doi: 10.1016/s0749-3797(98)00017-8

Fisher, J., Rowe, H., Wynter, K., Tran, T., Lorgelly, P., Amir, L. H., et al. (2016). Gender-informed, psychoeducational programme for couples to prevent postnatal common mental disorders among primiparous women: cluster randomised controlled trial. BMJ Open 6:e009396. doi: 10.1136/bmjopen-2015009396

Fisher, J. R. W., Wynter, K. H., and Rowe, H. J. (2010). Innovative psychoeducational program to prevent common postpartum mental disorders in primaparous women: a before and after controlled study. BMC Public Health 10:432. doi: 10.1186/1471-2458-10-432

Fonagy, P., Gergely, G., Jurist, E., and Target, M. (2002). Mentalization, Affective Regulation and the Development of the Self. New York, NY: Other Press.

Fonagy, P., Steele, M., Steele, H., Moran, G. S., and Higgitt, A. C. (1991). The capacity for understanding mental states: the reflective self in parent and child and its significance for security of attachment. Infant Ment. Health J. 12, 201-218. doi: 10.1002/1097-0355(199123)12:3<201::aid-imhj2280120307>3.0. co;2-7

Fonagy, P., and Target, M. (1997). Attachment and reflective function: their role in self-organization. Dev. Psychopathol. 9, 679-700. doi: 10.1017/ s0954579497001399

Giallo, R., D’Esposito, F., Cooklin, A., Mensah, F., Lucas, N., Wade, C., et al. (2013). Psychosocial risk factors associated with fathers' mental health in the postnatal period: Results from a population-based study. Soc. Psych. Psychiatr. Epidemiol. 48, 563-573. doi: 10.1007/s00127-012-0568-8

Gloaguen, V., Cottraux, J., Cucherat, M., and Blackburn, I. M. (1998). A metaanalysis of the effects of cognitive therapy in depressed patients. J. Affect. Disor. 49, 59-72.

Granot, D., and Mayseless, O. (2001). Attachment security and adjustment to school in middle childhood. Int. J. Behav. Dev. 25, 530-541. doi: 10.1080/ 01650250042000366

Green, J., and Goldwyn, R. (2002). Attachment disorganisation and psychopathology: new findings in attachment research and their potential implications for develoorderline personality symptoms at age 28. pmental psychopathology in childhood. J. Child Psychol. Psych. 43, 835-846.

Grienenberger, J. F., Kelly, K., and Slade, A. (2005). Maternal reflective functioning, mother infant affective communication, and infant attachment: exploring the link between mental states and observed caregiving behavior in the intergenerational transmission of attachment. Attach. Hum. Devel. 7, 299-311. doi: 10.1080/14616730500245963

Guild, D. J., Toth, S. L., Handley, E. D., Rogosch, F. A., and Cicchetti, D. (2017). Attachment security mediates the longitudinal association between childparent psychotherapy and peer relations for toddlers of depressed mothers. Dev. Psychopathol. 29, 587-600. doi: 10.1017/S0954579417000207

Guy, S., Furber, G., Leach, M., and Segal, L. (2016). How many children in Australia are at risk of adult mental illness. Aust. N. Z. J. Psychiatry 50, 1146-1160. doi: $10.1177 / 0004867416640098$

Halford, W. K., Petch, J., and Creedy, D. K. (2010). Promoting a positive transition to parenthood: a randomized clinical trial of couple relationship education. Prev. Sci. 11, 89-100. doi: 10.1007/s11121-009-0152-y

Hanington, L., Heron, J., Stein, A., and Ramchandani, P. (2012). Parental depression and child outcomes-is marital conflict the missing link? Child 38, 520-529. doi: 10.1111/j.1365-2214.2011.01270.x

Harold, G., Aitken, J., and Shelton, K. (2007). Inter-parental conflict and children's academic attainment: A longitudinal analysis. J. Child Psychol. Psych. 48, 12231232. doi: 10.1111/j.1469-7610.2007.01793.x

Harold, G., and Leve, L. (2012). "Parents and Partners: How the Parental Relationship affects Children's Psychological Development," in How Couple Relationships Shape Our World: Clinical Practice, Research, and Policy Perspectives, eds A. Balfour, M. Morgan, and C. Vincent (London: Karnac).

Havighurst, S. S., Kehoe, C. E., Harley, A. E., Johnson, A. M., Allen, N. B., and Thomas, R. L. (2019). Tuning in to Toddlers: research protocol and recruitment for evaluation of an emotion socialization program for parents and toddlers. Front. Psychol. 10:1054. doi: 10.3389/fpsyg.2019.01054

Hemmi, M. H., Wolke, D., and Schneider, S. (2011). Associations between problems with crying, sleeping and/or feeding in infancy and long-term behavioural outcomes in childhood: a meta-analysis. Arch. Dis. Child. 96, 622-629. doi: 10.1136/adc.2010.191312

Heron-Delaney, M., Kenardy, J. A., Brown, E. A., Jardine, C., Bogossian, F., Neuman, L., et al. (2016). Early maternal reflective functioning and infant emotional regulation in a preterm infant sample at 6 months corrected age. J. Pediatr. Psychol. 41, 906-914. doi: 10.1093/jpepsy/jsv169

Heyman, R. E., Smith Slep, A. M., Lorber, M. F., Mitnick, D. M., Xu, S., Baucom, K. J. W., et al. (2019). A randomized, controlled trial of the impact of the couple CARE for parents of newborns program on the prevention of intimate partner violence and relationship problems. Prev. Sci. 20, 620-631. doi: 10.1007/s11121018-0961-y

Hiscock, H., Bayer, J. K., Lycett, K., Ukoumunnee, O. C., Shaw, D., Gold, L., et al. (2012). Preventing mental health problems in children: the families in mind population-based cluster randomised controlled trial. BMC Public Health 12:420. doi: 10.1186/1471-2458-12-420

Hoffman, K. T., Marvin, R. R., Cooper, G., and Powell, B. (2006). Changing toddlers' and preschoolers' attachment classifications: the circle of security 
intervention. J. Consult. Clin. Psychol. 74, 1017-1026. doi: 10.1037/0022-006X. 74.6.1017

Holt, C., Gentilleau, C., Gemmill, A. W., and Milgrom, J. (2021). Improving the mother-infant relationship following postnatal depression: a randomised controlled trial of a brief intervention (HUGS). Arch. Womens. Ment. Health. doi: 10.1007/s00737-021-01116-5 [Epub ahead of print].

Horwitz, S. M., Hurlburt, M. S., Heneghan, A., Zhang, J., Rolls-Reutz, J., Landsverk, J., et al. (2013). Persistence of mental health problems in very young children investigated by US child welfare agencies. Acad. Pediatr. 13, 524-530. doi: 10.1016/j.acap.2013.06.001

Huberty, T. J. (2012). Anxiety and Depression in Children and Adolescents: Assessment, Intervention, and Prevention. New York, NY: Springer.

Jenkins, R., McCulloch, A., Friedli, L., and Parker, C. (2002). Developing a National Mental Health Policy. East Sussex: Psychology Press.

Johnson, J. E., Wiltsey-Stirman, S., Sikorski, A., Miller, T., King, A., Blume, J. L., et al. (2018). Protocol for the ROSE sustainment (ROSES) study, a sequential multiple assignment randomized trial to determine the minimum necessary intervention to maintain a postpartum depression prevention program in prenatal clinics serving low-income women. Implement. Sci. 13:115. doi: 10. 1186/s13012-018-0807-9

Jones, D., Feinberg, M., Hostetler, M., Roettger, M. E., Paul, A., and Ehrenthal, D. (2018a). Family and child outcomes 2 years after a transition to parenthood intervention. Family Relat. 67, 270-286. doi: 10.1111/fare.12309

Jones, D. E., Feinberg, M. E., and Hostetler, M. L. (2014). Costs to implement an effective transition-to-parenthood program for couples: analysis of the Family Foundations program. Eval. Prog. Plann. 44, 59-67. doi: 10.1016/j.evalprogplan. 2014.02.001

Jones, T. M., Nurius, P., Song, C., and Fleming, C. M. (2018b). Modeling life course pathways from adverse childhood experiences to adult mental health. Child Abuse Neglect 80, 32-40. doi: 10.1016/j.chiabu.2018.03.005

Kalland, M., Fagerlund, A., von Koskull, M., and Pajulo, M. (2016). Families first: the development of a new mentalization-based group intervention for first-time parents to promote child development and family health. Primary Health Care Res. Dev. 17, 3-17. doi: 10.1017/s146342361500016x

Karevold, E., Roysamb, E., Ystrom, E., and Mathiesen, K. S. (2009). Predictors and pathways from infancy to symptoms of anxiety and depression in early adolescence. Dev. Psychol. 45, 1051-1060. doi: 10.1037/a0016123

Keenan, K., Shaw, D., and Delliquadri, E. (1998). Evidence for the continuity of early problem behaviors: application of a developmental model. J. Abnorm. Child Psychol. 26, 441-452.

Kerns, K. A., and Brumariu, L. E. (2014). Is insecure parent-child attachment a risk factor for the development of anxiety in childhood or adolescence? Child Dev. Perspect. 8, 12-17. doi: 10.1111/cdep.12054

Kessler, R. C., Angermeyer, M., Anthony, J. C., DE Graaf, R., Demyttenaere, K., Gasquet, I., et al. (2007). Lifetime prevalence and age-of-onset distributions of mental disorders in the World Health Organization's World Mental Health Survey Initiative. World Psychiatry. 6, 168-176.

Kingston, D., Tough, S., and Whitfield, H. (2012). Prenatal and postpartum maternal psychological distress and infant development: a systematic review. Child Psychiatry Hum. Dev. 43, 683-714. doi: 10.1007/s10578-012-0291-4

Kohlhoff, J., Stein, M., Ha, M., and Mejaha, K. (2016). The circle of security parenting (COS-P) intervention: pilot evaluation. Aust. J. Child Family Health Nurs. 13:3.

Lakens, D. (2013). Calculating and reporting effect sizes to facilitate cumulative science: a practical primer for t-tests and ANOVAs. Front. Psychol. 4:863. doi: 10.3389/fpsyg.2013.00863

Lally, J. R., and Mangione, P. (2017). Caring relationships: the heart of early brain development. Young Children 72, 1-11. Available online at: www.naeyc.org/resources/pubs/yc/may2017/caring-relationships-heart-earlybrain-development (accessed November 26, 2020).

Lancaster, C. A., Gold, K. J., Flynn, H. A., Yoo, H., Marcus, S. M., and Davis, M. M. (2010). Risk factors for depressive symptoms during pregnancy: A systematic review. Am. J. Obstetr. Gynecol. 202, 5-14. doi: 10.1016/j.ajog.2009. 09.007

Landry, S. H., Smith, K. E., and Swank, P. R. (2006). Responsive parenting: establishing early foundations for social, communication, and independent problem-solving skills. Dev. Psychol. 42, 637-642. doi: 10.1037/0012-1649.42. 4.627
Landry, S. H., Smith, K. E., Swank, P. R., and Guttentag, C. (2008). Responsive parenting intervention: the optimal timing across early childhood for impacting maternal behaviors and child outcomes. Dev. Psychol. 44, 1335-1353. doi: 10. 1037/a0013030

Landry, S. H., Zucker, T. A., Taylor, H. B., Swank, P. R., Williams, J. M., Assel, M., et al. (2014). Enhancing early child care quality and learning for toddlers at risk: the responsive early childhood program. Dev. Psychol. 50, 526-541. doi: $10.1037 / \mathrm{a} 0033494$

Lauw, M. S. M., Havighurst, S. S., Wilson, K., Harley, A., and Northam, E. A. (2014). Improving parenting of toddlers' emotions using an emotion coaching parenting program: a pilot study of Tuning in to Toddlers. J. Commun. Psychol. 42, 169-175. doi: 10.1002/jcop. 21602

Lavigne, J. V., Arend, R., Rosenbaum, D., Binns, H. J., Christoffel, K. K., and Gibbons, R. D. (1998). Psychiatric disorders with onset in the preschool years: I. Stability of diagnoses. J. Am. Acad. Child Adolesc. Psychiatry 37, 1246-1254. doi: 10.1097/00004583-199812000-00007

Lawrence, E., Rothman, A. D., Cobb, R. J., Rothman, M. T., and Bradbury, T. N. (2008). Marital satisfaction across the transition to parenthood. J. Family Psychol. 22, 41. doi: 10.1037/0893-3200.22.1.41

Le, H., Perry, D. F., and Stuart, E. A. (2011). Randomized controlled trial of a preventive intervention for perinatal depression in high-risk Latinas. J. Consult. Clin. Psychol. 79, 135-141. doi: 10.1037/a0022492

Le, Y., McDaniel, B. T., Leavitt, C. E., and Feinberg, M. E. (2016). Longitudinal associations between relationship quality and coparenting across the transition to parenthood: A dyadic perspective. J. Fam. Psychol. 30, 918-926. doi: 10.1037/ fam0000217

Leis, J. A., Solomon, B. S., Wasserman, K. E., Carter, T. N., Mendelson, T., Perry, D. F., et al. (2015). Preventing postpartum depression in a pediatric primary care clinic: a pilot study. Clin. Pediatr. 54, 487-490. doi: 10.1177/ 0009922814536775

Lewis, A. J., Galbally, M., Gannon, T., and Symeonides, C. (2014). Early life programming as a target for prevention of child and adolescent mental disorders. BMC Med. 12:33. doi: 10.1186/1741-7015-12-33

Linville, D., Chronister, K., Dishion, T., Todahl, J., Miller, J., Shaw, D., et al. (2010). A longitudinal analysis of parenting practices, couple satisfaction, and child behavior problems. J. Marit. Fam. Ther. 36, 244-255. doi: 10.1111/j.1752-0606. 2009.00168.x

Loeber, R., Burke, J. D., Lahey, B. B., Winters, Z., and Zera, M. (2009). Oppositional defiant and conduct disorder: a review of the past 10 years. J. Am. Acad. Child Adolesc. Psychiatry. 39, 1468-1484. doi: 10.1097/00004583-20001200000007

Love, J. M., Kisker, E. E., Ross, C., Raikes, H., Constantine, J., Boller, K., et al. (2005). The effectiveness of early head start for 3-year-old children and their parents: lessons for policy and programs. Dev. Psychol. 41, 885-901. doi: 10.1037/00121649.41.6.885

Lyons-Ruth, K. (2003). Dissociation and the parent-infant dialogue: A longitudinal perspective from attachment research. Attachment 9, 253-276. doi: 10.1177/ 00030651030510031501

Lyons-Ruth, K., Todd Manly, J., Von Klitzing, K., Tamminen, T., Emde, R., Fitzgerald, H., et al. (2017). The worldwide burden of infant mental and emotional disorder: report of the task force of the world association for infant mental health. Infant Ment. Health J. 38, 695-705. doi: 10.1002/imhj. 21674

Madigan, S., Atkinson, L., Laurin, K., and Benoit, D. (2013). Attachment and internalizing behavior in early childhood: a meta-analysis. Dev. Psychol. 49, 672-689. doi: 10.1037/a0028793

Macdonald, H. Z., Beeghly, M., Grant-Knight, W., Augustyn, M., Woods, R. W., Cabral, H., et al. (2008). Longitudinal association between infant disorganized attachment and childhood posttraumatic stress symptoms. Dev. Psychopathol. 20, 493-503. doi: 10.1017/S0954579408000242

Maldonado-Duran, J. M., Lartigue, T., and Feintuch, M. (2000). Perinatal psychiatry: infant mental health interventions during pregnancy. Bull. Menninger Clin. 64, 317-343.

Maskell-Graham, D. (2014). Peep Reflective Parenting Programme (Pilot): A therapeutic intervention beginning in late pregnancy. Available online at: www.peeple.org.uk/sites/www.peeple.org.uk/files/Reflective $\% 20$ Parenting\%20Study\%20-\%20Interim\%20Findings\%20Summary.pdf (accessed November 3, 2020). 
McCarty, C. A., Zimmerman, F. J., Digiuseppe, D. L., and Christakis, D. A. (2005). Parental emotional support and subsequent internalizing and externalizing problems among children. J. Dev. Behav. Pediatr. 26, 267-275. doi: 10.1097/ 00004703-200508000-00002

McFarlane, E., Burrell, L., Duggan, A., and Tandon, D. (2017). Outcomes of a randomized trial of a cognitive behavioral enhancement to address maternal distress in home visited mothers. Matern. Child Health J. 21, 475-484. doi: 10.1007/s10995-016-2125-7

McLuckie, A., Landers, A. L., Curran, J. A., Cann, R., Carrese, D. H., Nolan, A., et al. (2019). A scoping review of mental health prevention and intervention initiatives for infants and preschoolers at risk for socio-emotional difficulties. Syst. Rev. 8:183. doi: 10.1186/s13643-019-1043-3

Mendelson, T., Leis, J. A., Perry, D. F., Stuart, E. A., and Tandon, S. D. (2013). Impact of a preventative intervention for perinatal depression on mood regulation, social support, and coping. Arch. Womens Ment. Health 16, 211218. doi: 10.1007/s00737-013-0332-4

Mihelic, M., Morawska, A., and Filus, A. (2017). Effects of early parenting interventions on parents and infants: a meta-analytic review. J. Child Family Stud. 26, 1507-1526. doi: 10.1007/s10826-017-0675-y

Milgrom, J., Ericksen, J., McCarthy, R., and Gemmill, A. W. (2006). Stressful impact of depression on early mother-infant relations. Stress Health 22, 229-238. doi: 10.1002/smi.1101

Milgrom, J., and Holt, C. (2014). Early intervention to protect the mother-infant relationship following postnatal depression: study protocol for a randomised controlled trial. Trials 15:385.

Milgrom, J., Schembri, C., Ericksen, J., Ross, J., and Gemmill, A. W. (2011). Towards parenthood: an antenatal intervention to reduce depression, anxiety and parenting difficulties. J. Affect. Disord. 130, 385-394. doi: 10.1016/j.jad. 2010.10.045

Miller, M. (2012). Boot Camp for New Dads: Report of workshop surveys. Available online at: www.bootcampfornewdads.org/validating-research/ (accessed December 11, 2019).

Miner, J. L., and Clarke-Stewart, A. (2008). Trajectories of externalizing behavior from age 2 to age 9: relations with gender, temperament, ethnicity parenting, and rater. Dev. Psychol. 44, 771-786. doi: 10.1037/0012-1649.44.3.771

Moore, T., Arefadib, N., Deery, A., and West, S. (2017). The First Thousand Days: An Evidence Paper. Parkeville, VIC: Centre for Community Child Health.

Mothander, P. R., Furmack, C., and Neander, K. (2018). Adding "Circle of Security - Parenting" to treatment as usual in three Swedish infant mental health clinics. Effects on parents' internal representations and quality of parentinfant interaction. Scand. J. Psychol. 59, 262-272. doi: 10.1111/sjop.12419

Munoz, R. F., Le, H., Ippen, C. G., Diaz, M. A., Urizar, G. G., Soto, J., et al. (2007). Prevention of postpartum depression in low-income women: development of the Mamas y bebes/Mother and Babies course. Cogn. Behav. Pract. 14, 70-83. doi: 10.1016/j.cbpra.2006.04.021

Muzik, M., Rosenblum, K., Schuster, M., Kohler, E. S., Alfafara, E., and Miller, N. (2016). A mental health and parenting intervention for adolescent and young adult mothers and their infants. J. Depress. Anxiety 5:233. doi: 10.4172/21671044.1000233

Muzik, M., Rosenblum, K. L., Alfafara, E. A., Schuster, M. M., Miller, N. M., Waddell, R. M., et al. (2015). Mom power: preliminary outcomes of a group intervention to improve mental health and parenting among high-risk mothers. Arch. Womens Ment. Health 18, 507-521. doi: 10.1007/s00737-014-0490-z

National Scientific Council on the Developing Child (2008). Mental Health Problems in Early Childhood Can Impair Learning and Behavior for Life. Working paper No. 6. National Scientific Council on the Developing Child. Cambridge, MA: Harvard University.

Newman, L., Judd, F., Olsson, C. A., Castle, D., Bousman, C., Sheehan, P., et al. (2016). Early origins of mental disorder-risk factors in the perinatal and infant period. BMC Psychiatry 16:270. doi: 10.1186/s12888-016-0982-7

Nicolson, S., Judd, F., Thomson-Salo, F., and Mitchell, S. (2013). Supporting the adolescent mother-infant relationship: preliminary trial of a brief perinatal attachment intervention. Arch. Womens Ment. Health 16, 511-520. doi: 10. 1007/s00737-013-0364-9

O’Brien, A. P., McNeil, K. A., Fletcher, R., Conrad, A., Wilson, A. J., Jones, D., et al. (2017). New fathers' perinatal depression and anxiety - treatment options: an integrative review. Ment. Health Wellbeing 11, 863-876. doi: 10.1177/ 1557988316669047
PANDA. (2017). Contributing Factors for Postnatal Depression or Anxiety. Available online at: https://www.panda.org.au/info-support/after-birth/contributingfactors-for-postnatal-depression-or-anxiety (accessed November 26, 2020).

Parlakian, R., and Seibel, N. (2002). Building Strong Foundations: Practical Guidance for Promoting the Social-Emotional Development of Infants and Toddlers. Washington, DC: ZERO TO THREE Press, 2002.

Pedro, M. F., Ribeiro, T., and Shelton, K. H. (2012). Marital satisfaction and partners' parenting practices: The mediating role of coparenting behavior. J. Fam. Psychol. 26:509. doi: 10.1037/a0029121

Perry, B. D. (2004). Maltreated Children: Experience, Brain Development, and the Next Generation. New York, NY: W.W. Norton.

Petch, J. F., Halford, W. K., Creedy, D. K., and Gamble, J. (2012). A randomized controlled trial of a couple relationship and coparenting program (Couple CARE for Parents) for high-and low-risk new parents. J. Consult. Clin. Psychol. 80, 662-673. doi: 10.1037/a0028781

Philpott, L. F., and Corcoran, P. (2018). Paternal postnatal depression in Ireland: prevalence and associated factors. Midwifery 56, 121-127. doi: 10.1016/j.midw. 2017.10.009

Pike, A., Iervolino, A. C., Eley, T., Price, T. S., and Plomin, R. (2006). Environmental risk and young children's cognitive and behavioral development. Int. J. Behav. Dev. 30, 55-56. doi: 10.1177/01650254060 62124

Pilkington, P. D., Whelan, T. A., and Milne, L. C. (2015). A review of partnerinclusive interventions for preventing postnatal depression and anxiety. Clin. Psychol. 19, 63-75. doi: 10.1111/cp.12054

Ponnet, K., Mortelmans, D., Wouters, E., Van Leeuwen, K., Bastaits, K., and Pasteels, I. (2013). Parenting stress and marital relationship as determinants of mothers' and fathers' parenting. Personal Relat. 20, 259-276. doi: 10.1111/ j.1475-6811.2012.01404.x

Popp, L., Fuths, S., and Schneider, S. (2019). The relevance of infant outcome measures: a pilot-RCT comparing Baby Triple $\mathrm{P}$ positive parenting program with care as usual. Front. Psychol. 10:2425. doi: 10.3389/fpsyg.2019.02425

Postert, C., Averbeck-Holocher, M., Achtergarde, S., Müller, J. M., and Furniss, T. (2012). Regulatory disorders in early childhood: correlates in child behavior, parent-child relationship, and parental mental health. Infant Ment. Health J. 33, 173-186. doi: 10.1002/imhj.20338

Raikes, H. J., and Love, J. M. (2002). Early head start: a dynamic new program for infants and toddlers and their families. Infant Ment. Health J. 23, 1-13. doi: 10.1002/imhj.10000

Rapee, R. M., Schniering, C. A., and Hudson, J. L. (2009). Anxiety disorders during childhood and adolescence: origins and treatment. Annu. Rev. Clin. Psychol. 5, 311-341. doi: 10.1146/annurev.clinpsy.032408.153628

Robinson, M., Oddy, W., Li, J., Kendall, G. E., De Klerk, N. H., Silburn, S. R., et al. (2008). Pre- postnatal influences on preschool mental health: a large cohort study. J. Child Psychol. 49, 1118-1128. doi: 10.1111/j.1469-7610.2008. 01955.x

Rose, J., Roman, N., and Mwaba, K. (2018). Circle of Security parenting program efficacy for improving parental self-efficacy in a South African setting: preliminary evidence. J. Psychol. Afr. 28, 518-521. doi: 10.1080/14330237.2018. 1523308

Rosenblum, K. L., McDonough, S., Sameroff, A. J., and Muzik, M. (2008). Reflection in thought and action: maternal parenting reflectivity predicts mindminded comments and interactive behavior. Infant Ment. Health J. 29, 362-376. doi: 10.10002/imhj.20184

Rosenblum, K., Lawler, J., Alfafara, E., Miller, N., Schuster, M., and Muzik, M. (2018). Improving maternal representations in high-risk mothers: a randomized, controlled trial of the Mom Power parenting intervention. Child Psychiatry Hum. Dev. 48, 372-384. doi: 10.1007/s10578-0170757-5

Rosenblum, K. L., Muzik, M., Morelen, D. M., Alfafara, E. A., Miller, N. M., Waddell, R. M., et al. (2017). A community-based randomized controlled trial of Mom Power parenting intervention for mothers with interpersonal trauma histories and their young children. Arch. Womens Ment. Health 20, 673-686. doi: 10.1007/s00737-017-0734-9

Sadler, L. S., Slade, A., Close, N., Webb, D. L., Simpson, T., Fennie, K., et al. (2013). Minding the baby: enhancing reflectiveness to improve early health and relationship outcomes in an interdisciplinary home-visiting program. Infant Ment. Health J. 34, 391-405. doi: 10.1002/imhj.21406 
Saias, T., Greacen, T., Tubach, F., Dugravier, R., Marcault, E., Tereno, S., et al. (2013). Supporting families in challenging contexts: the CAPEDP project. Glob. Health Promot. 20, 66-70. doi: 10.1177/17579759134 83335

Sarkadi, A., Kristiansson, R., Oberklaid, F., and Bremberg, S. (2008). Fathers' involvement and children's developmental outcomes: a systematic review of longitudinal studies. Acra Paediatr. 97, 153-158. doi: 10.1111/j.1651-2227. 2007.00572.x

Schneider, B., Atkinson, L., and Tardif, C. (2001). Child-parent attachment and children's peer relations: a quantitative review. Dev. Psychol. 37, 86-100. doi: 10.1037/0012-1649.37.1.86

Shaw, D. S., Gilliom, M., and Ingoldsby, E. M. (2003). Trajectories leading to school-age conduct problems. Dev. Psychol. 39, 189-200. doi: 10.1037/00121649.39.2.189

Shonkoff, J. P., Garner, A. S., The Committee on Psychosocial Aspects of Child and Family Health, Committee on Early Childhood, Adoption, and Dependent Care, and Section on Developmental and Behavioral Pediatrics. (2012). The lifelong effects of early childhood adversity and toxic stress. Pediatrics 129 , e232-e246. doi: 10.1542/peds.2011-2663

Skovgaard, A. M., Houmann, T., Christiansen, E., Landorph, S., Jørgensen, T., Olsen, E., et al. (2007). The prevalence of mental health problems in children $1^{1 / 2}$ years of age - the Copenhagen Child Cohort 2000. J. Child Psychol. Psychiatry 48, 62-70. doi: 10.1111/j.1469-7610.2006.01659.x

Slade, A., Grienenberger, J., Bernbach, E., Levy, D., and Locker, A. (2005a). Maternal reflective functioning, attachment, and the transmission gap: A preliminary study. Attach. Hum. Devel. 7, 283-298. doi: 10.1080/ 14616730500245880

Slade, A., Holland, M. L., Ordway, M. R., Carlson, E. A., Jeon, S., Close, N., et al. (2020). Minding the Baby ${ }^{\circledR}$ : enhancing parental reflective functioning and infant attachment in an attachment-based, interdisciplinary home visiting program. Dev. Psychopathol. 32, 123-137. doi: 10.1017/S095457941800 1463

Slade, A., Sadler, L., Dios-Kenn, C., Webb, D., Currier-Ezepchick, J., and Mayes, L. (2005b). Minding the Baby: a reflective parenting program. Psychoanal. Stud. Child 60, 74-100. doi: 10.1080/00797308.2005.11800747

Slemming, K., Sørensen, M., Thomsen, P., Obel, C., Henriksen, T., and Linnet, K. (2010). The association between preschool behavioural problems and internalizing difficulties at age 10-12 years. Eur. Child Adolesc. Psychiatry 19:787. doi: 10.1007/s00787-010-0128-2

Smaling, H. J., Huijbregts, S. C., van der Heijden, K. B., Hay, D. F., van Goozen, S. H., and Swaab, H. (2016). Prenatal reflective functioning and development of aggression in infancy: the roles of maternal intrusiveness and sensitivity. J. Abnorm. Child Psychol. 45, 237-248. doi: 10.1007/s10802-016-0177-1

Sockol, L. E. (2015). A systematic review of the efficacy of cognitive behavioural therapy for treating and preventing perinatal depression. J. Affect. Disor. 177, $7-21$.

Sroufe, L. A. (2005). Attachment and development: a prospective, longitudinal study from birth to adulthood. Attach. Hum. Dev. 7, 349-367. doi: 10.1080/ 14616730500365928

Stacks, A. M., Muzik, M., Wong, K., Beeghly, M., Huth-Bocks, A., Irwin, J. L., et al. (2014). Maternal reflective functioning among mothers with childhood maltreatment histories: links to sensitive parenting and infant attachment security. Attach. Hum. Devel. 16, 515-533. doi: 10.1080/14616734.2014.935452

Steele, H., and Siever, L. (2010). An attachment perspective on borderline personality disorder: Advances in gene-environment considerations. Curr. Psych. Rep. 12, 61-67. doi: 10.1007/s11920-009-0091-0

Suchman, N. E., DeCoste, C., Leigh, D., and Borelli, J. (2010). Reflective functioning in mothers with drug use disorders: implications for dyadic interactions with infants and toddlers. Attach. Hum. Devel. 12, 567-585. doi: 10.1080/14616734. 2010.501988

Suveg, C., Southam-Gerow, M. A., and Goodman, K. L. (2007). The role of emotion theory and research in child therapy development. Clin. Psychol. 14, 358-371.

Tandon, S. D., Leis, J. A., Mendelson, T., Perry, D. F., and Kemp, K. (2014). Six-month outcomes from a randomized controlled trial to prevent perinatal depression in low-income home visiting clients. Matern. Child Health J. 18, 873-881. doi: 10.1007/s10995-013-1313-y

Tandon, S. D., Perry, D. F., Mendelson, T., Kemp, K., and Leis, J. A. (2011). Preventing perinatal depression in low-income home visiting clients: a randomized controlled trial. J. Consult. Clin. Psychol. 79, 707-712. doi: 10.1037/ a0024895

Tandon, S. D., Ward, E. A., Hamil, J. L., Jimenez, C., and Carter, M. (2018). Perinatal depression prevention though home visitation: a cluster randomised trial of mothers and babies 1-on-1. J. Behav. Med. 41, 641-652. doi: 10.1007/ s10865-018-9934-7

The National Health and Medical Research Council (2017). NHMRC Report on the Evidence: Promoting Social and Emotional Development and Wellbeing of Infants in Pregnancy and the First Year of Life. Canberra: NHMRC.

Thomas, N., Komiti, A., and Judd, F. (2014). Pilot early intervention antenatal group program for pregnant women with anxiety and depression. Arch. Womens Ment. Health 17, 503-509. doi: 10.1007/s00737-014-0447-2

Tomlinson, M., Bornstein, M. H., Marlow, M., and Swartz, L. (2014). Imbalances in the knowledge about infant mental health in rich and poor countries: too little progress in bridging the gap. Infant Ment. Health J. 35, 624-629. doi: 10.1002/imhj.21462

Tsivos, Z., Calam, R., Sanders, M. R., and Wittkowski, A. (2015). A pilot randomised controlled trial to evaluate the feasibility and acceptability of the Baby Triple P Positive Parenting Programme in mothers with postnatal depression. Clin. Child Psychol. Psychiatry 20, 532-554. doi: 10.1177/ 1359104514531589

Teubert, D., and Pinquart, M. (2010). The association between coparenting and child adjustment: A meta-analysis. Parenting 10, 286-307. doi: 10.1080/ 15295192.2010.492040

Trillingsgaard, T., Baucom, K. J., and Heyman, R. E. (2014). Predictors of change in relationship satisfaction during the transition to parenthood. Family Relat. 63, 667-679. doi: 10.1111/fare.12089

Van Ijzendoorn, M. H., Schuengel, C., and Bakermans-Kranenburg, M. (1999). Disorganized attachment in early childhood: Meta-analysis of precursors, concomitants, and sequelae. Devel. Psychopathol. 11, 225-249. doi: 10.1017/ S0954579499002035

Van Ravesteyn, L. M., Lambregtse, M., Hoogendijk, J. G., and Kamperman, A. (2017). Interventions to treat mental disorders during pregnancy: a systematic review and multiple treatment meta-analysis. PLoS One 12:e0173397. doi: 10. 1371/journal.pone.0173397

Van Zeijl, J., Mesman, J., Stolk, M. N., Alink, L. R. A., van Ijzendoorn, M. H., Bakermans-Kranenburg, M. J., et al. (2006). Terrible ones? Assessment of externalizing behaviors in infancy with the child behavior checklist. J. Child Psychol. Psychiatry 47, 801-810. doi: 10.1111/j.1469-7610.2006.01616.x

Vieten, C., and Astin, J. (2008). Effects of a mindfulness-based intervention during pregnancy on prenatal stress and mood: results of a pilot study. Arch. Womens Ment. Health 11, 67-74. doi: 10.1007/s00737-008-0214-

von Klitzing, K., Dohnert, M., Kroll, M., and Grube, M. (2015). Mental disorders in early childhood. Deutsches Arzteblatt Int. 112, 375-386. doi: 10.3238/arztebl. 2015.0375

Waddell, C., Hua, J. M., Garland, O. M., Peters, R., and McEwan, K. (2007). Preventing mental disorders in children: a systematic review to inform policymaking. Rev. Can. Sante Publique 98, 166-173. doi: 10.1007/bf03403706

Warner, L. A., and Pottick, K. J. (2006). Functional impairment among preschoolers using mental health services. Children Youth Serv. Rev. 28, 473486. doi: 10.1016/j.childyouth.2005.11.008

Watson, J., White, A., Taplin, S., and Huntsman, L. (2005). Prevention and Early Intervention Literature Review. Sydney, NSW: NSW Centre for Parenting and Research.

Werner, E. A., Gustafsson, H. C., Lee, S., Feng, T., Jiang, N., Desai, P., et al. (2016). PREPP: postpartum depression prevention through the mother-infant dyad. Arch. Womens Ment. Health 19, 229-242. doi: 10.1007/s00737-015-0549-5

Whisman, M. A., Davila, J., and Goodman, S. H. (2011). Relationship adjustment, depression, and anxiety during pregnancy and the postpartum period. J. Fam. Psychol. 25:375. doi: 10.1037/a0023790

Wlodarczyk, O., Pawils, S., Metzner, F., Kriston, L., Klasen, F., Ravens-Sieberer, U., et al. (2017). Risk and protective factors for mental health problems in preschool-aged children: cross-sectional results of the BELLA preschool study. Child Adolesc. Psychiatry Ment. Health 11:12. doi: 10.1186/s13034-017-0149-4

Woody, C. A., Ferrari, A. J., Siskind, D. J., Whiteford, H. A., and Harris, M. G. (2017). A systematic review and meta-regression of the prevalence and incidence of perinatal depression. J. Affect. Disord. 219, 86-92. doi: 10.1016/j. jad.2017.05.003 
World Health Organization (2003). Caring for Children and Adolescents with Mental Disorders: Setting WHO Directions. Geneva: WHO.

World Health Organization (2004). Prevention of Mental Disorders: Effective Interventions and Policy Options. Geneva: World Health Organization.

Yaholkoski, A., Hurl, K., and Theule, J. (2016). Efficacy of the circle of security intervention: a meta-analysis. J. Infant Child Adolesc. Psychother. 15, 95-103. doi: 10.1080/15289168.2016.1163161

Yap, M. B. H., Pilkington, P. D., Ryan, S. M., and Jorm, A. F. (2014). Parental factors associated with depression and anxiety in young people: A systematic review and meta-analysis. J. Affect. Disor. 156, 8-23. doi: 10.1016/j.jad.2013.11.007

Zero to Three (2012). Making It Happen: Overcoming Barriers to Providing InfantEarly Childhood Mental Health. Washington, DC: Zero to Three.

ZERO TO THREE (2016). DC0-5. Diagnostic Classification of Mental Health and Developmental Disorders of Infancy and Early Childhood. Washignton, DC: ZERO TO THREE. doi: 10.1016/j.jaac.2018.07.843

Ziemeng, M., Ying, L. M. D., and Jiayao, W. M. D. (2020). Effectiveness of cognitive behavioural therapy for perinatal deprssion: A systematic review and meta-analysis. J. Clin Nurs. 29, 3170-3182. doi: 10.1111/jocn.15378

Zlotnick, C., Johnson, S., Miller, I., Pearlstein, T., and Howard, M. (2001). Postpartum depression in women receiving public assistance: pilot study of an interpersonal-therapy-oriented group intervention. Am. J. Psychiatry 158, 638-640. doi: 10.1176/appi.ajp.158.4.638
Zlotnick, C., Miller, I. W., Pearlstein, T., Howard, M., and Sweeney, P. (2006). A preventative intervention for pregnant women on public assistance at risk for postpartum depression. Am. J. Psychiatry 163, 1443-1445. doi: 10.1176/appi.ajp. 163.8.1443

Conflict of Interest: The authors declare that the research was conducted in the absence of any commercial or financial relationships that could be construed as a potential conflict of interest.

Publisher's Note: All claims expressed in this article are solely those of the authors and do not necessarily represent those of their affiliated organizations, or those of the publisher, the editors and the reviewers. Any product that may be evaluated in this article, or claim that may be made by its manufacturer, is not guaranteed or endorsed by the publisher.

Copyright (c) 2021 Izett, Rooney, Prescott, De Palma and McDevitt. This is an openaccess article distributed under the terms of the Creative Commons Attribution License (CC BY). The use, distribution or reproduction in other forums is permitted, provided the original author(s) and the copyright owner(s) are credited and that the original publication in this journal is cited, in accordance with accepted academic practice. No use, distribution or reproduction is permitted which does not comply with these terms. 